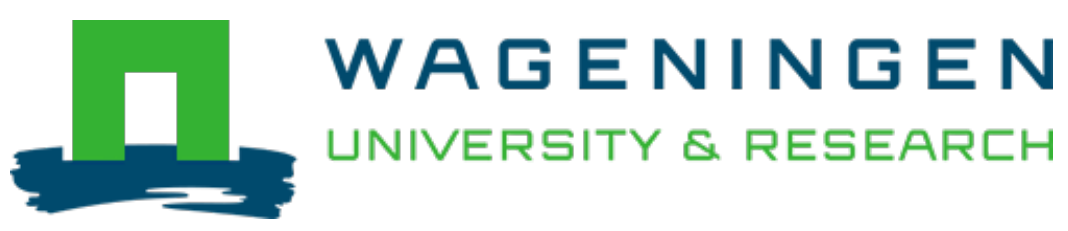

\title{
Zwitterionic dendrimer - Polymer hybrid copolymers for self-assembling antifouling coatings
}

\author{
European Polymer Journal \\ Roeven, Esther; Scheres, Luc; Smulders, Maarten M.J.; Zuilhof, Han \\ https://doi.org/10.1016/j.eurpolymj.2021.110578
}

This article is made publicly available in the institutional repository of Wageningen University and Research, under the terms of article $25 \mathrm{fa}$ of the Dutch Copyright Act, also known as the Amendment Taverne. This has been done with explicit consent by the author.

Article 25 fa states that the author of a short scientific work funded either wholly or partially by Dutch public funds is entitled to make that work publicly available for no consideration following a reasonable period of time after the work was first published, provided that clear reference is made to the source of the first publication of the work.

This publication is distributed under The Association of Universities in the Netherlands (VSNU) 'Article $25 \mathrm{fa}$ implementation' project. In this project research outputs of researchers employed by Dutch Universities that comply with the legal requirements of Article $25 \mathrm{fa}$ of the Dutch Copyright Act are distributed online and free of cost or other barriers in institutional repositories. Research outputs are distributed six months after their first online publication in the original published version and with proper attribution to the source of the original publication.

You are permitted to download and use the publication for personal purposes. All rights remain with the author(s) and / or copyright owner(s) of this work. Any use of the publication or parts of it other than authorised under article $25 \mathrm{fa}$ of the Dutch Copyright act is prohibited. Wageningen University \& Research and the author(s) of this publication shall not be held responsible or liable for any damages resulting from your (re)use of this publication.

For questions regarding the public availability of this article please contact openscience.library@,wur.nl 


\title{
Zwitterionic dendrimer - Polymer hybrid copolymers for self-assembling antifouling coatings
}

\author{
Esther Roeven $^{\mathrm{a}, \mathrm{b}}$, Luc Scheres ${ }^{\mathrm{b}}$, Maarten M.J. Smulders ${ }^{\mathrm{a}, *}$, Han Zuilhof ${ }^{\mathrm{a}, \mathrm{c}, \mathrm{d}, \text {, }}$

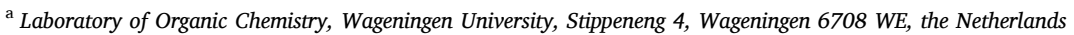 \\ ${ }^{\mathrm{b}}$ Surfix BV, Bronland $12 \mathrm{~B}-1$, Wageningen $6708 \mathrm{WH}$, the Netherlands \\ ' School of Pharmaceutical Sciences and Technology, Tianjin University, 92 Weijin Road, Tianjin 300072, People's Republic of China \\ ${ }^{\mathrm{d}}$ Department of Chemical and Materials Engineering, Faculty of Engineering, King Abdulaziz University, 21589 Jeddah, Saudi Arabia
}

\section{A R T I C L E I N F O}

\section{Keywords:}

Dendrimer

Antifouling coating

Surface chemistry

Macromolecule

Zwitterionic

PLL

\begin{abstract}
A B S T R A C T
In this work, we show two different routes to synthesize polymer-dendrimer hybrids by the coupling of poly(Llysine) and zwitterionic dendrimers (ZIDs). Poly(L-lysine) (PLL) is used because of its advantageous self-assembly properties onto silicon oxide by charged-based interactions between the lysine groups and the negatively charged surface, whilst the coupled ZIDs provide antifouling properties. The first route yields network-like structures in which PLL and ZIDs are crosslinked by multiple amide bonds. By using different ratios of PLL and ZID, we vary the size of the formed networks. A more defined, linear PLL-ZID macromolecule is formed via coupling of multiple ZIDs to PLL in a controlled way by a copper-catalyzed azide/alkyne cycloaddition (CuAAC) "click" reaction. Following synthesis and characterization of the two different types of PLL-ZID macromolecules, they are self-assembled on silicon oxide surfaces from aqueous solutions in a single step, to form thin, hydrophilic coatings. Their potential use as antifouling coatings is tested by fluorescence microscopy and quartz crystal microbalance (QCM) with foulants such a single proteins and diluted human serum. Finally, by performing an on-surface biofunctionalization step by biotin we demonstrate it is possible to use these polymer-dendrimer hybrids for selective detection of target analytes (here: streptavidin), while the underlying coating maintains its antifouling properties.

This method presents a new, straightforward approach for the manufacturing of PLL-ZID based coatings that can be pre-synthesized partly or fully and applied as coating in a single self-assembly step. Both steps can take place in aqueous solution and under ambient conditions, and result in stable coatings that not only display antifouling properties but also maintain the possibility of further functionalization.
\end{abstract}

\section{Introduction}

Most synthetic polymers are linear or only moderately branched. In contrast, dendrimers are a class of macromolecules with precisely defined, highly branched structures and are obtained by sequential reactions through divergent or convergent synthesis [1-5]. As a result, they possess a distinct molecular architecture with a core, branches and terminal functional groups. The high level of control over dendritic architectures, the presence of internal cavities and the possibility for multivalent binding have, for example, focused attention on dendrimers as potential carriers in biomedical applications $[3,4,6]$. While dendrimers modified with charged groups have found use for in vivo drug delivery, the presence of a high density of charged groups on the dendrimer structure also enables an entirely new application that has so far been largely overlooked. That is, highly charged dendrimers with no net charge, i.e. zwitterionic dendrimers (ZID) are potentially very interesting for surface chemistry applications since zwitterionic coatings have been shown to drastically reduce (bio)fouling of surfaces when applied as a coating $[7,8]$. Previously, charged dendrimers have been used as coating, although mainly in layer-by-layer approaches where alternating layers of positively and negatively charged dendrimers were assembled on a surface $[2,9,10]$. In contrast, the use of a fully and permanently zwitterionic dendrimer-based coating has not been reported in literature. So far, only the use of (partially) zwitterionic dendrimers has been reported for use in other biomedical applications such as drug delivery, sensing and MRI contrast agents [11,12,21,13-20].

\footnotetext{
* Corresponding authors.

E-mail addresses: Maarten.Smulders@wur.nl (M.M.J. Smulders), Han.Zuilhof@wur.nl (H. Zuilhof).
} 
Building blocks for a new type of zwitterionic antifouling coating should have a high density of opposite charges, creating a strong zwitterionic character, while remaining overall neutral [22]. We chose to work with zwitterionic dendrimers as building blocks as they uniquely combine a well-defined and monodisperse nature with a relatively large size, and the possibility for multivalent coupling towards surface immobilization, crosslinking or eventually biofunctionalization. In our lab, fully zwitterionic, carboxybetaine dendrimers were previously developed [21]. Additionally, also zwitterionic dendrimers (ZID) that contain a variable number of alkyne and azide groups that allow coupling by click chemistry were synthesized [21]. In search for a method to strongly bind these ZIDs to a surface as a coating, we selected poly(L-lysine) (PLL) to covalently couple the ZID to. PLL is known for its affinity towards, e.g., silicon oxide, metal oxide and polymeric surfaces [23-28]. The polymer self-assembles to silicon oxide at $\mathrm{pH}>2$, driven by multiple electrostatic attractions between the negatively charged surface and the positively charged pendant amine groups present in PLL $[29,30]$. For example, a well-known and widely used combination of PLL with antifouling side groups is poly(L-lysine)-graft-poly(ethylene glycol) (PLL-g-PEG) [23-28]. In other studies, also the coupling of different antifouling polymers to a PLL backbone was shown to result in coatings with antifouling properties $[25,31]$. However, to the best of our knowledge, no combination of linear polymers and zwitterionic dendrimers has been investigated before for use as antifouling coating.

For other applications, the unique combination of linear and dendritic copolymers was first described in the beginning of 1990s by the group of Fréchet [32-34]. Subsequently, other research groups have developed block [35-37], star [38,39], linearly alternating lineardendrimer hybrid architectures [34], crosslinked superstructures [40], and brush-like polymers with dendritic side chains [41-43]. These resulting linear-dendritic hybrids showed very interesting properties in terms of self-assembly, enhanced solubility and reduced toxicity and immunogenicity $[33,44]$.

Here we report the synthesis of two different architectures of dendrimer-PLL hybrids that were connected in two different ways (Fig. 1). First we explored the random cross-coupling of the carboxylic acid groups of the carboxybetaine ZIDs and the terminal amine groups on the PLL in three different ZID:PLL ratios. This should create a large polymer network in which the ZID acts as crosslinking agent of the linear PLL chains. Next to this, a more controlled way of coupling the ZID to PLL was investigated. Namely, via the creation of specific covalent bonds to obtain a well-defined, non-networked macrostructure. The coupling between the ZID and PLL was established by a coppercatalyzed azide/alkyne cycloaddition (CuAAC) reaction [45] between a single terminal alkyne group on the ZID [21] and terminal azide groups on a commercially available azide-modified PLL. These two PLLZID macromolecules were first synthesized and characterized in solution (by techniques including NMR, DOSY and IR) prior to surface immobilization. In this study, silicon oxide was used as a model substrate because of its relevance in, e.g., biosensors [46] and microfluidic devices [47]. After self-assembly on silicon oxide surfaces, the formed coatings were investigated using water contact angle (WCA) measurements and X-ray photoelectron spectroscopy (XPS).

To investigate the potential perspective of the use of such PLL-ZID macromolecular coatings for antifouling purposes, we performed an investigation of the antifouling performance obtained for these hybrid PLL-ZID copolymer approaches. Quantitative protein adsorption onto a surface has been investigated by a variety of techniques, such as surface plasmon resonance (SPR), optical waveguide devices, atomic force microscopy (AFM) and ellipsometry [25,48-51]. Here, we first used fluorescence to study the protein repellence of fluorescently labeled proteins. The antifouling properties of selected PLL-ZID coatings against single proteins and human serum were subsequently studied in more detail with quartz crystal microbalance (QCM) studies. Finally, an onsurface biofunctionalization step by biotin was performed by activation of the carboxylate groups and reacting them with amino-biotin for the selective detection of streptavidin, while maintaining antifouling properties.

\section{Results and discussion}

We will first discuss the synthesis, characterization and surface immobilization of the poly(L-lysine)-zwitterionic dendrimer (PLL-ZID) networks. After that, the linear PLL-ZID macrostructures will be

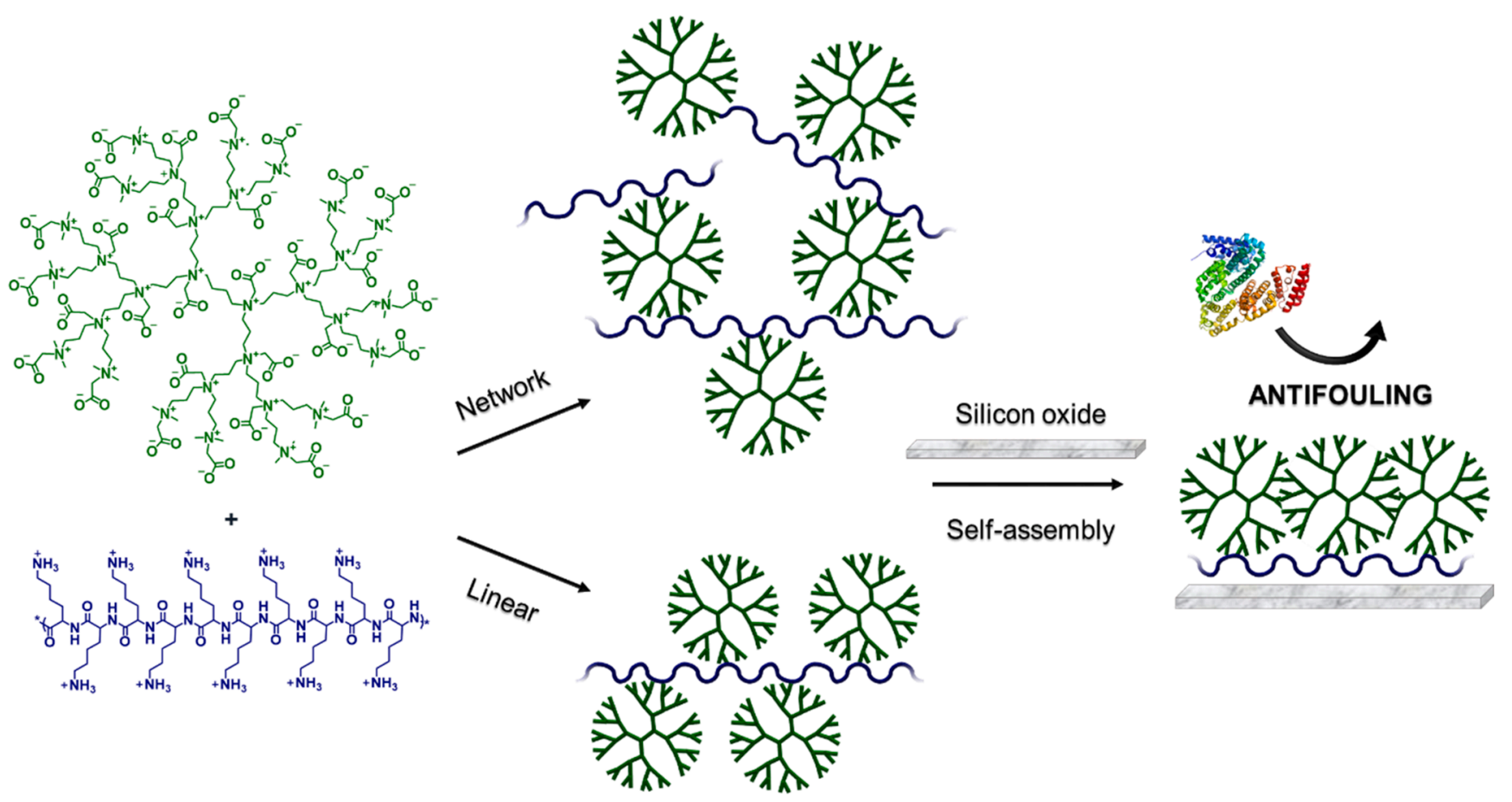

Fig. 1. Molecular structure of ZID and PLL (left), and (schematically) their coupling into hybrid PLL-ZID macromolecules (as network or linear structure) and subsequent surface immobilization to create antifouling coatings. 
discussed in a similar fashion. Subsequently, the antifouling studies on the formed coatings as measured by fluorescence and QCM will be discussed and evaluated.

\subsection{Synthesis and characterization of poly(L-lysine)-zwitterionic dendrimer (PLL-ZID) networks}

To obtain the poly(L-lysine)-zwitterionic dendrimer (PLL-ZID) networks, a suitable coupling reaction between the zwitterionic dendrimer and the PLL polymer backbone was needed. The presence of a carboxylic acid group on the former, and an amine group on the latter, prompted us to achieve the coupling via amide bond formation, as this is a widely used for the bioconjugation of carboxybetaine zwitterionic polymers (Fig. 2) [52-55].

The amide bond formation was performed by activation of the carboxylate groups on the dendrimer using $N$-hydroxysuccinimide (NHS)/1-ethyl-3-[3-dimethylaminopropyl]-carbodiimide hydrochloride (EDC) chemistry [53]. As both reactants in this coupling reaction contain a high number of (potentially) reacting groups (i.e. $\sim 100$ lysines on PLL and $\sim 30$ carboxylate groups on the dendrimer), it was anticipated that depending on the ratio between the two reactants different network structures could be formed. Therefore, three different ratios of ZID:PLL were explored to form the networks, which we labelled as Netw_A, Netw_B and Netw_C (see Table 1 for their feed ratio).

After letting the NHS-mediated amide coupling reaction run for $24 \mathrm{~h}$, the mixture was extensively dialyzed against water to remove all lowmolecular weight species (unreacted EDC and NHS, buffer salts, etc.). After freeze-drying, the obtained product was first of all characterized by ${ }^{1} \mathrm{H}$ NMR spectroscopy, revealing the presence of both the ZID and PLL component in the product. The ratio between the ZID and PLL signals showed an expected trend in line with the different ratios in starting materials (Fig. 3). The shift of peaks $e, b$ and $g$ to $e^{*}, b^{*}$ and $g^{*}$, respectively, in Fig. 3 indicates binding of ZID to PLL via amide bonds. Although all PLL-ZID networks were extensively dialyzed, especially in Netw_A, there seems to be more ZID present than can be explained by the amide bond formation. This suggests that, apart from the formed covalent bonds, most likely also charged-based interactions contribute to binding between PLL and ZID, which is not unsurprising given the
Table 1

Different ratios of ZID : PLL used in the formation of PLL-ZID networks expressed in molar, reactive group and mass ratios.

\begin{tabular}{|c|c|c|c|c|c|c|}
\hline & \multicolumn{2}{|c|}{ Molar ratio } & \multicolumn{2}{|c|}{ Reactive group ratio } & \multicolumn{2}{|c|}{ Mass ratio } \\
\hline & PLL & ZID & LYS & $\mathrm{COO}^{-}$ & PLL & ZID \\
\hline Netw_A & 1 & 5000 & 1 & 1500 & 1 & 720 \\
\hline Netw_B & 1 & 500 & 1 & 150 & 1 & 72 \\
\hline Netw_C & 1 & 50 & 1 & 15 & 1 & 7.2 \\
\hline
\end{tabular}

highly charged nature of both components. Apart from the newly formed signals $e^{*}, b^{*}$ and $g^{*}$, also the original signals were still present, implying that not all available amide and carboxylate groups reacted, which can be understood considering the steric clash that would occur at high or full conversion. The incomplete conversion can be further attributed to the fact that this reaction was performed at $\mathrm{pH} 6$, meaning that not all reactive groups are in the correct protonation state $\left(\mathrm{p} K_{\mathrm{a}}^{\mathrm{LYS}} \sim 10\right.$ and $\mathrm{p} K_{\mathrm{a}}^{\mathrm{COO}-} \sim 2$; the latter low $\mathrm{p} K_{\mathrm{a}}$ value is due to the short distance between the carboxyl group and the cationic site $[56,57]$ ), whereas the NHS coupling reaction is unsuccessful at both acidic and alkaline $\mathrm{pH}$ [58]. Such incomplete conversion is, however, in this case desirable, as for the surface binding it is essential to still have unreacted lysine groups available. Additionally, infrared (IR) spectroscopy on the three networks also showed the expected varying in signals origination from PLL and ZID (see SI). However, no newly formed amide signals could be observed since PLL as one of the starting materials already is a polyamide.

Diffusion-ordered spectroscopy (DOSY) allowed us to assess the dimensions of the three formed networks. The PLL-ZID networks with Netw_B and Netw_C yielded hydrodynamic volumes of $1.5 \times 10^{3}$ and $1.2 \times 10^{3} \mathrm{~nm}^{3}$, respectively, whereas the PLL starting material had a hydrodynamic volume of $8.6 \times 10^{2} \mathrm{~nm}^{3}$ (see SI, Table S1). An individual ZID molecule has an estimated volume of $20 \mathrm{~nm}^{3}$ [21]. Based on the increase in hydrodynamic volume, we infer that -on average- some tens of dendrimers are linked to the PLL backbone. Unfortunately, for Netw_A the ${ }^{1} \mathrm{H}$ spectrum was dominated by residual unbound ZID in such a way that no DOSY trace for the PLL-ZID network signals could be obtained.

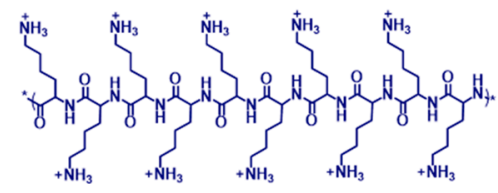

PLL (21 kDa, DP 100)

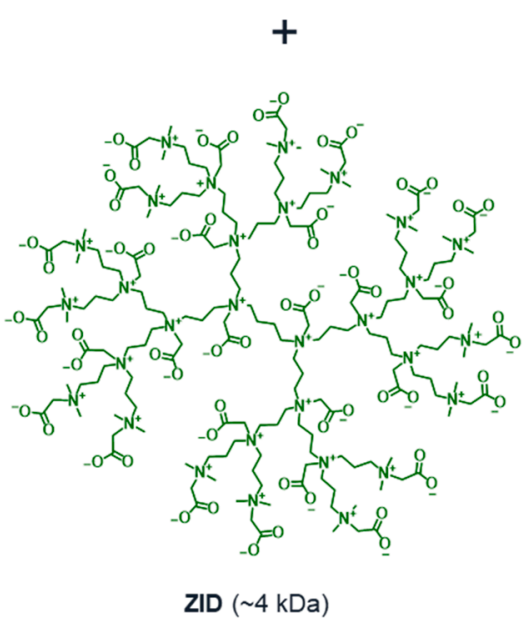

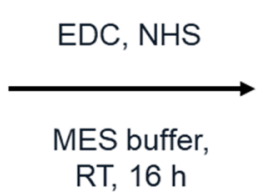

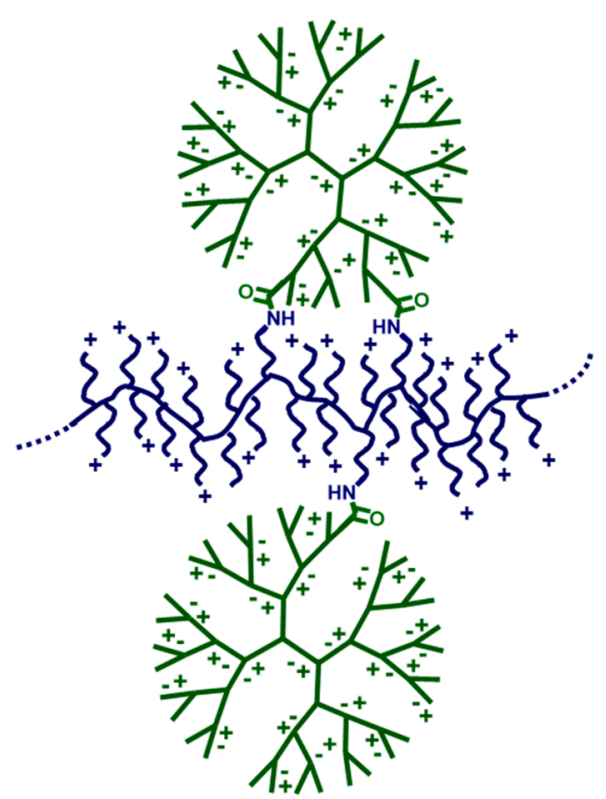

Netw_A, B, C

Fig. 2. Schematic depiction of the formation of the PLL-Z8ID networks via NHS/EDC mediated amide bond formation. 

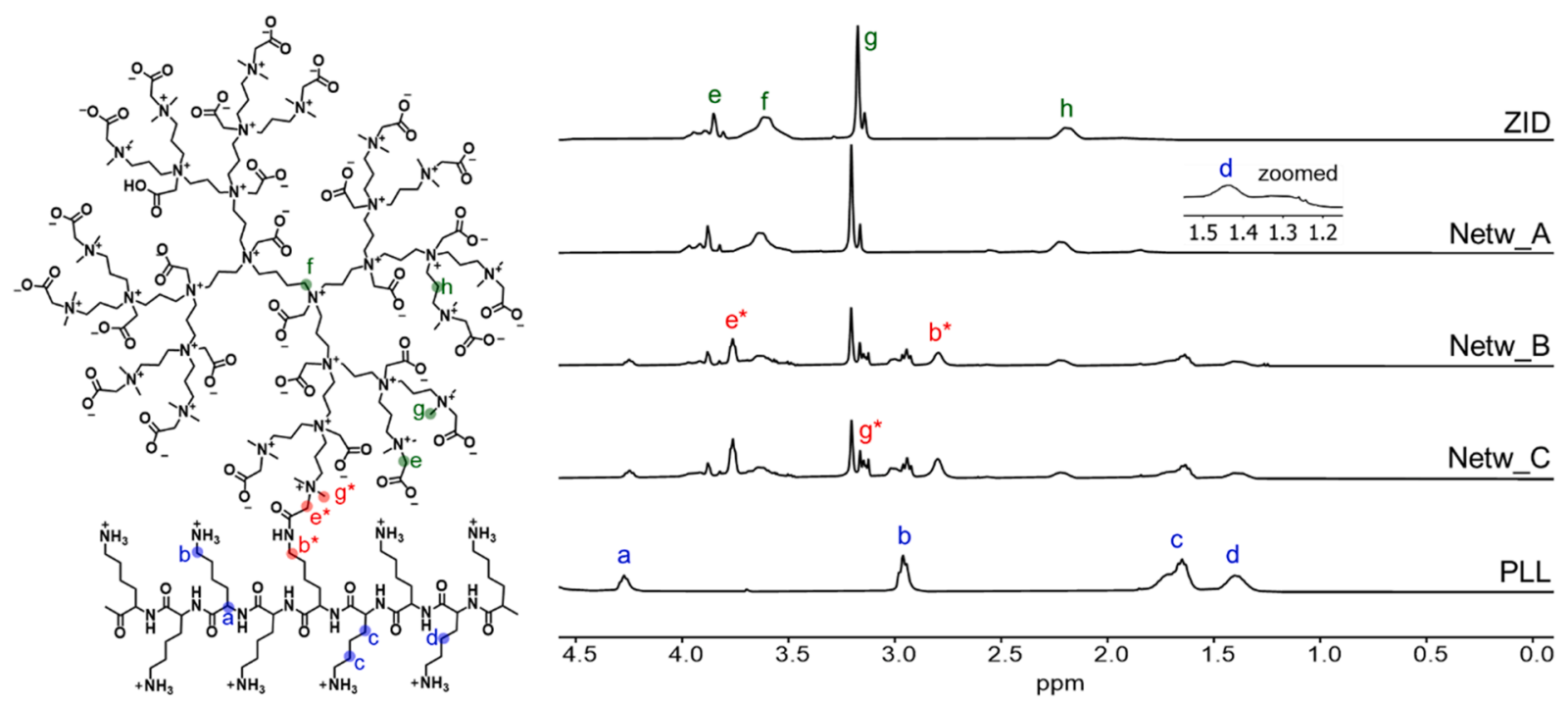

Fig. 3. ${ }^{1} \mathrm{H}$ NMR spectrum of the PLL-ZID networks and starting materials. From top to bottom: ZID, Netw_A, Netw_B, Netw_C and PLL (in D 20 , 400 MHz, 298 K). The inset for Netw_A is a zoomed-in fraction of the Netw_A spectrum to show the presence of the small PLL signal $d$.

\subsection{Surface immobilization of the PLL-ZID networks}

In order to form an antifouling coating by PLL-ZID networks, this crosslinked polymer network was self-assembled onto the surface by charged-based interactions between the free (protonated) terminal amine moieties of the lysine groups of PLL and the negatively charged silicon oxide surface, according to established protocols (Fig. 4) [28,59].

Once immobilized, the ZIDs should provide antifouling properties to the surface. To this end, PLL-ZID networks were self-assembled by overnight immersion of freshly cleaned, negatively charged silicon oxide surfaces in a $0.1 \mathrm{mg} / \mathrm{mL}$ solution of PLL-ZID in HEPES buffer, followed by washing with HEPES buffer and MilliQ water (following previously reported procedures $[25,31]$ ). XPS analysis of the coatings made by Netw_A, Netw_B and Netw_C was performed. Additionally, coatings with unfunctionalized PLL were made as a reference and also characterized by XPS. All the obtained coatings showed signals for $\mathrm{N}\left(\mathrm{N}_{1 \mathrm{~s}}\right.$ at $400 \mathrm{eV})$ and $\mathrm{C}\left(\mathrm{C}_{1 \mathrm{~s}}\right.$ at $\left.285 \mathrm{eV}\right)$ on the silicon oxide surfaces, which is in agreement with the presence of the polymer network (Fig. 5).
Furthermore, the three PLL-ZID network coatings have a higher signal for $\mathrm{O}\left(\mathrm{O}_{1 \mathrm{~s}}\right.$ at $\left.530 \mathrm{eV}\right)$, which can be ascribed to the carboxylate groups in ZID. The layer thickness of the PLL and PLL-ZID network coatings were calculated using the $\mathrm{Si} / \mathrm{C}$ ratio in the XPS wide scan to calculate the average thickness of the layers, $[60,61]$ and was found to be $0.7 \mathrm{~nm}$ for PLL and approximately $0.8 \mathrm{~nm}$ for all the networks. Such a low layer thickness for a surface-immobilized polymer is in agreement with other types of surface-immobilized PLL-based bottlebrushes reported in literature [23-25], and typically attributed to the ultra-high vacuum conditions of XPS thickness measurements that yield a collapsed polymer layer that will expand upon immersion in solution.

The $\mathrm{N}_{1 \mathrm{~s}}$ narrow scan of the coating made by PLL revealed peaks at $399.8 \mathrm{eV}$ and $402.0 \mathrm{eV}$, which originated from non-protonated and protonated lysine amine moieties, respectively. The ZID-PLL networks showed an additional peak at $403.0 \mathrm{eV}$, which can be attributed to the dendrimer's quaternary $\mathrm{N}^{+}$. Similar to the trend observed by ${ }^{1} \mathrm{H}$ NMR spectroscopy for the three networks, the $\mathrm{N}_{1 \mathrm{~s}}$ narrow scans also showed an increase in the amount of incorporated ZIDs via an increased fraction

\section{PLL-ZID network Self-assembly HEPES buffer $16 \mathrm{~h}, \mathrm{RT}$}

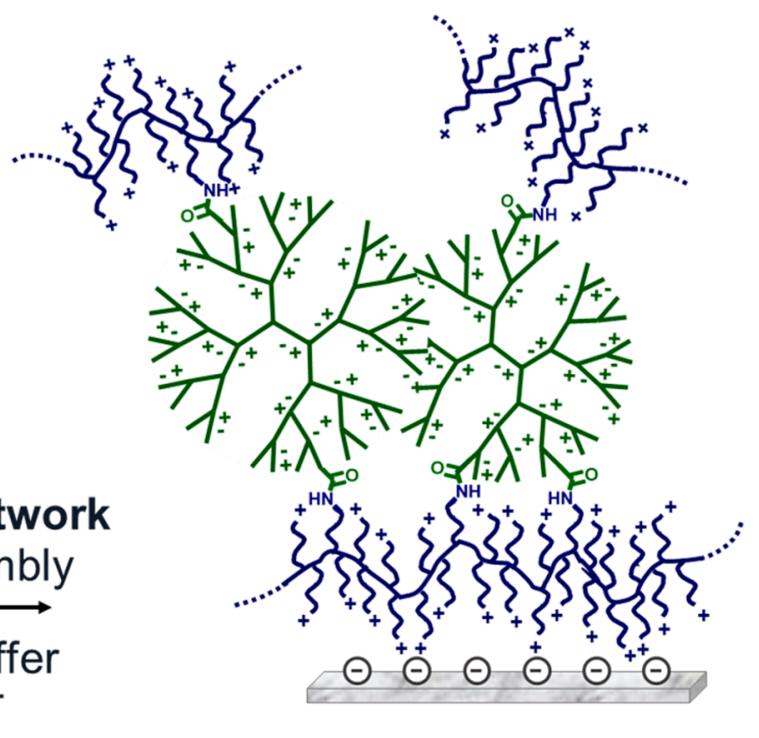

\section{Silicon oxide}

Fig. 4. Schematic depiction of the self-assembly of a PLL-ZID network onto a silicon oxide surface. 

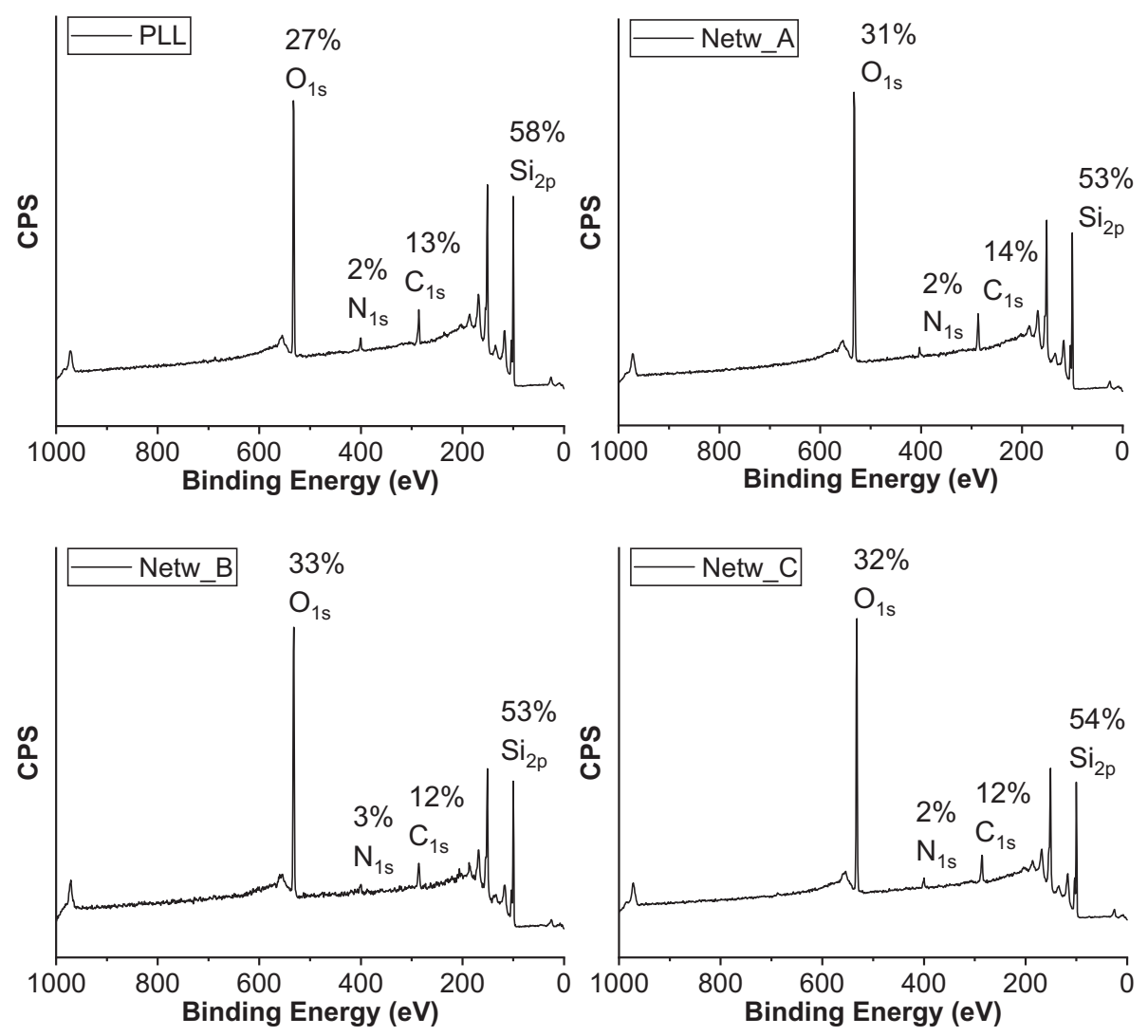

Fig. 5. XPS wide spectra of the surface-immobilized PLL and PLL-ZID networks Netw_A, Netw_B and Netw_C.
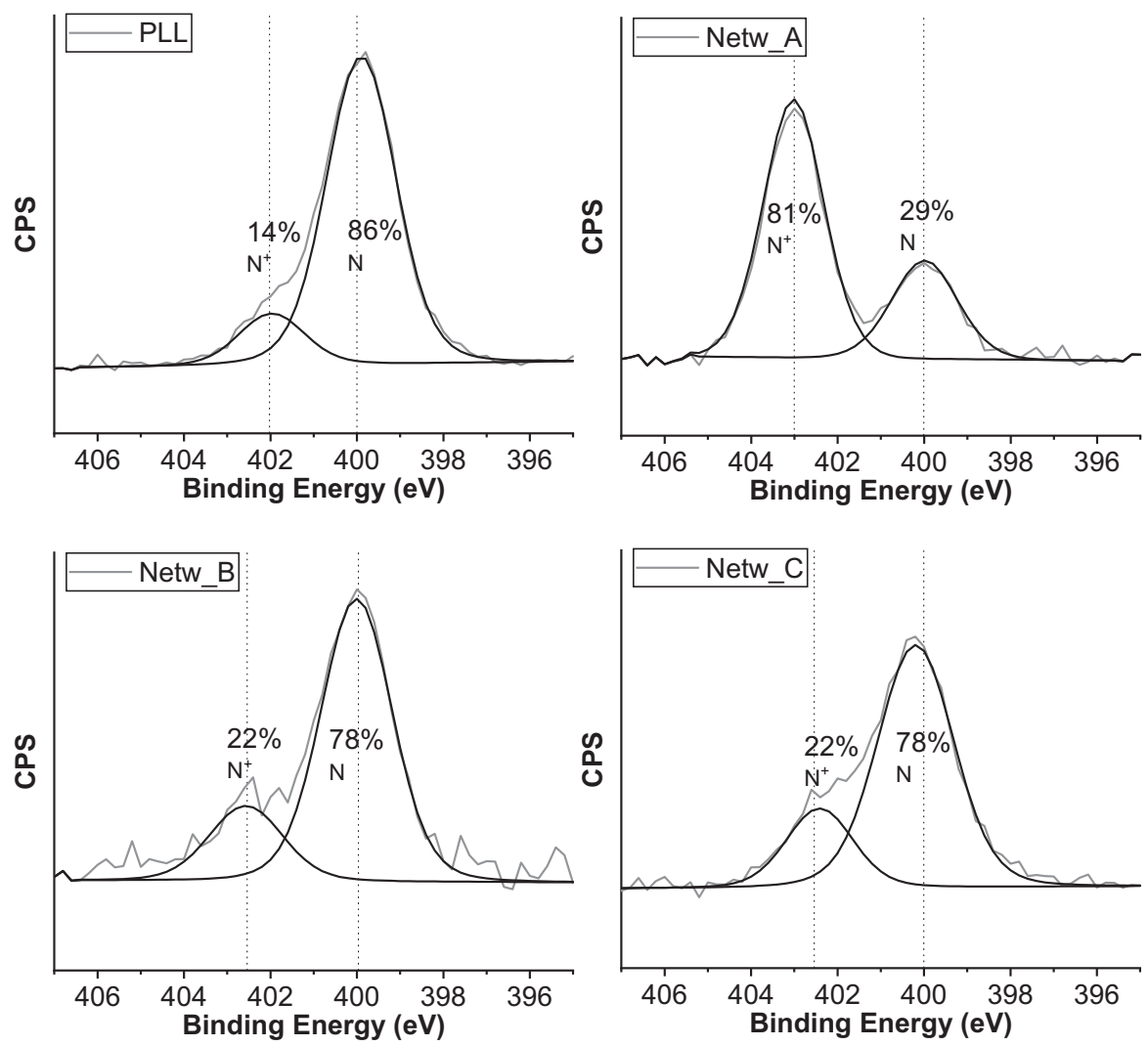

Fig. 6. XPS $\mathrm{N}_{1 \mathrm{~s}}$ narrow spectra of surface-immobilized Netw_A, Netw_B and Netw_C and PLL. 
of the ZID-based quaternary nitrogen atoms (Fig. 6).

Additionally, the water contact angle (WCA) of all coatings made by Netw_A, Netw_B and Netw_C displayed full wetting, compared to the WCA of the PLL coating being $<20^{\circ}$, but remaining a droplet on the surface. By eye, a clear difference in hydrophilicity was observed but unfortunately the difference could not be quantified due to the lower limit of angle detection of the WCA setup. The high hydrophilicity can be ascribed to the ZIDs which are attached to the PLL.

Combining all data shows that a macromolecular PLL-ZID network is formed via a combination of covalent amine bonds and charge-based interactions. These PLL-ZID networks can be applied as coatings that will self-assemble onto silicon oxide. While possible, the presence of charge-based binding of additional ZID units reduced the degree of definition of the resulting coatings. In order to find a more defined macromolecular structure, a second type binding strategy was studied. This strategy involved the incorporation of a defined number of complementary functional groups on PLL and ZID, respectively that will react to form a covalent bond, which should lead to linear PLL-ZID macrostructures.

\subsection{Synthesis and characterization of linear PLL-ZID macrostructures by click chemistry}

To obtain poly(L-lysine)-zwitterionic dendrimer (PLL-ZID) macrostructures with a well-defined, linear macrostructure, we set out to form covalent bonds by a Cu-catalyzed azide/alkyne cycloaddition (CuAAC) reaction between a single terminal alkyne group on the ZID and terminal azide groups on a commercially available azide-modified PLL (one out of five lysines contains an azide group) [45]. Since we used ZIDs containing one alkyne group, as previously reported by our group [21]. This system leads to a better defined product compared to the more random networks that have multiple possible interactions between PLL and a single ZID (Fig. 7).

After letting the CuAAC reaction run overnight at $40{ }^{\circ} \mathrm{C}$, the mixture was extensively dialyzed against water to remove the copper sulfate and sodium ascorbate. After freeze-drying, the presence of both the ZID and PLL in the product was confirmed by ${ }^{1} \mathrm{H}$ NMR spectroscopy (Fig. 8). Direct evidence for the success of the reaction is the triazole proton signal at $\delta 8.02 \mathrm{ppm}$. While this is a relatively small signal as a result of the large overall hybrid macromolecular structure, it could definitely be discerned in the ${ }^{1} \mathrm{H}$ NMR spectrum. When normalizing the integrals to the ZID signal $e$ ( $\delta 2.14 \mathrm{ppm})$, the integral ratio of this signal compared to $a$ (triazole, $\delta 8.02 \mathrm{ppm}$ ) and $f$ (PLL, $\delta 1.34 \mathrm{ppm}$ ) would imply a conversion of approximately $90 \%$ of all PLL-based azide groups in the CuAAC reaction. Since the integration of peaks $a$ and $f$ is rather difficult, we treat this value only to mean that a significant fraction of the azide groups has reacted (see XPS-based data below for a more precise determination). Unfortunately, the ${ }^{1} \mathrm{H}$ spectrum was dominated by residual unbound ZID in such a way, that no DOSY trace for the Lin_A signals could be obtained.

Additionally, infrared (IR) spectroscopy showed the disappearance of the characteristic azide signal (at $2108 \mathrm{~cm}^{-1}$ ) upon reaction with the ZID's alkyne moiety in the CuAAC reaction, next to the expected signals for the ZID and PLL (Fig. S10 in the SI).

\subsection{Surface immobilization of linear PLL-ZID}

The linear PLL-ZID Lin_A was self-assembled onto silicon oxide in a similar fashion as described for the PLL-ZID networks (see Fig. 9). Upon washing and drying, the coating made by Lin_A was analyzed using XPS. Again, the XPS wide scan showed signals for N (at $400 \mathrm{eV}$ ) and C (285 $\mathrm{eV}$ ) on the silicon oxide surfaces, which confirms the formation of the polymer network (Fig. 10). The layer thickness of the Lin_A PLL-ZID was calculated based om the $\mathrm{Si} / \mathrm{C}$ ratio in the XPS wide scan and was found to be approximately $1.0 \mathrm{~nm}$. Also here, the relatively thin layer is due to the collapsed polymer layer in the ultra-high vacuum within the XPS machine. The observed dry thickness was in line with the thicknesses of the PLL $(0.7 \mathrm{~nm})$ and the PLL-ZID networks Netw_A, Netw_B, Netw_C (all approximately $0.8 \mathrm{~nm}$ ).

The XPS $\mathrm{N}_{1 \mathrm{~s}}$ scan showed the characteristic peaks for neutral (400.0

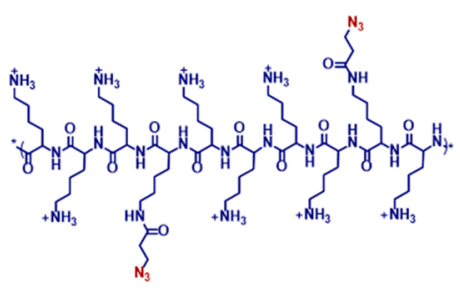

PLL (azide grafted (20\%), $32 \mathrm{kDa})$
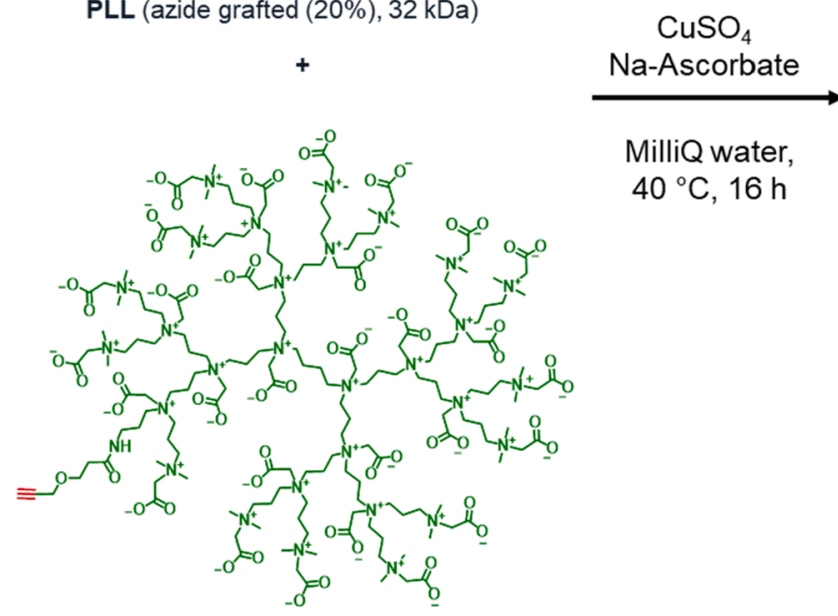

ZID (n=1 alkyne, $4 \mathrm{kDa}$ )

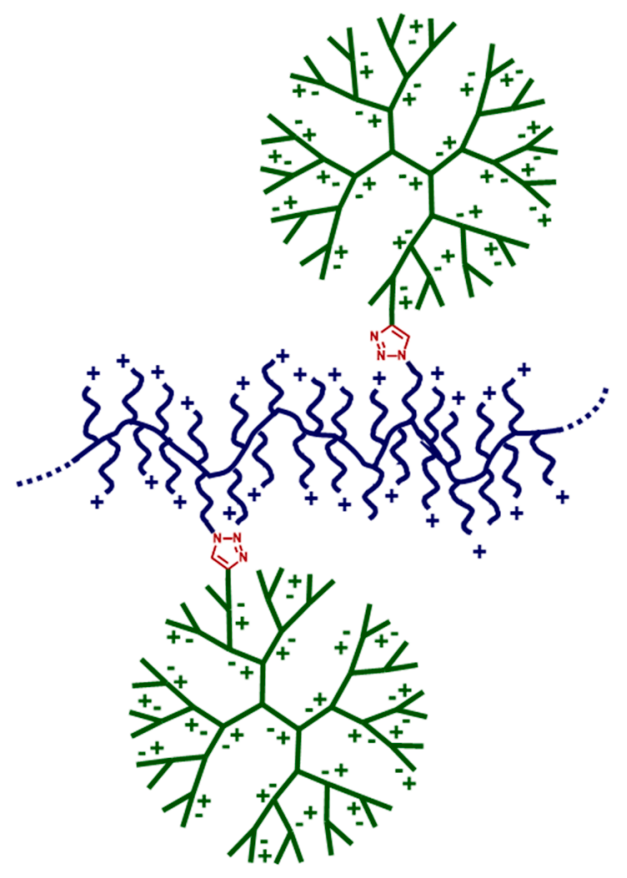

Lin_A

Fig. 7. Schematic depiction of the formation of the linear PLL-ZID macrostructure Lin_A via copper(I)-mediated triazole ring formation. 


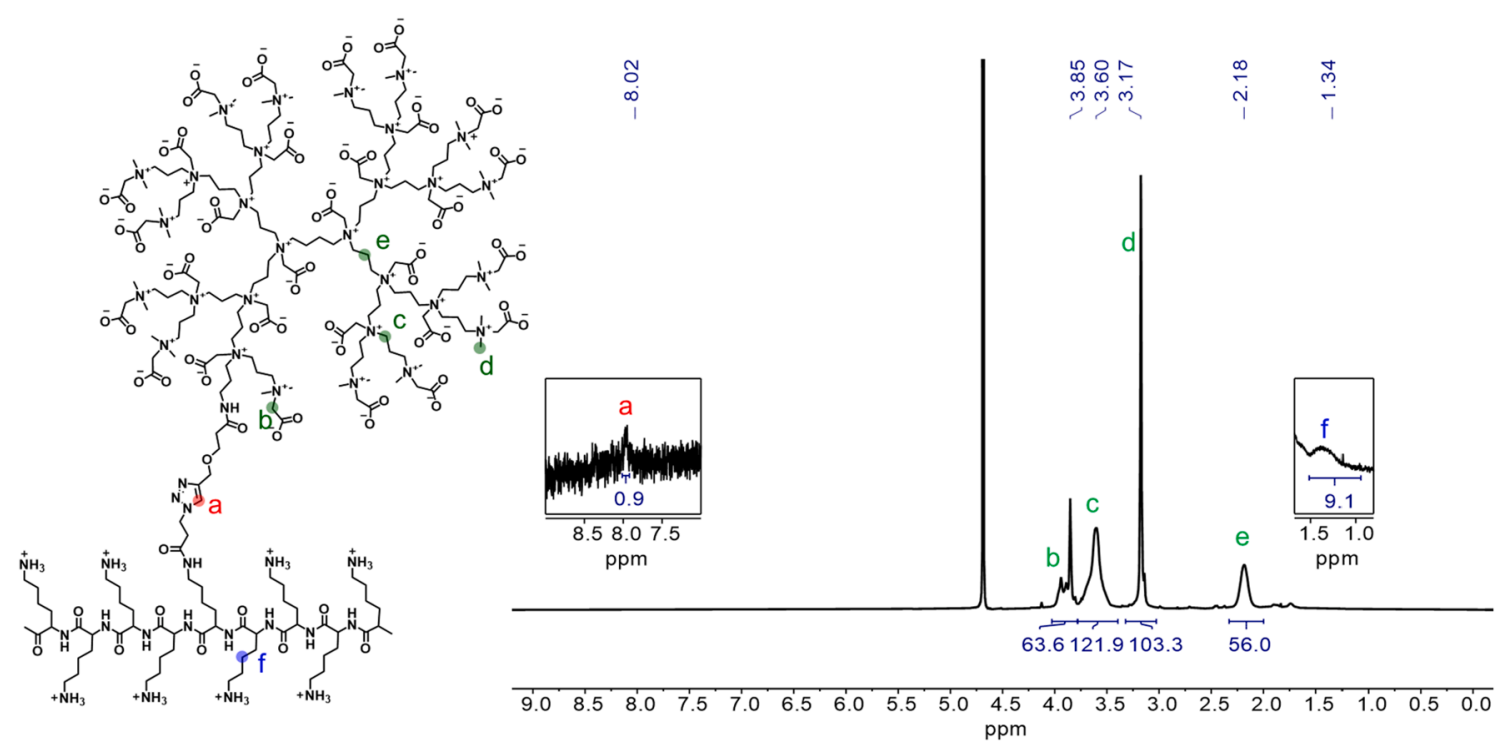

Fig. 8. ${ }^{1} \mathrm{H}$ NMR spectrum of the linear PLL-ZID macrostructure Lin_A (in $\mathrm{D}_{2} \mathrm{O}, 400 \mathrm{MHz}, 298 \mathrm{~K}$ ).
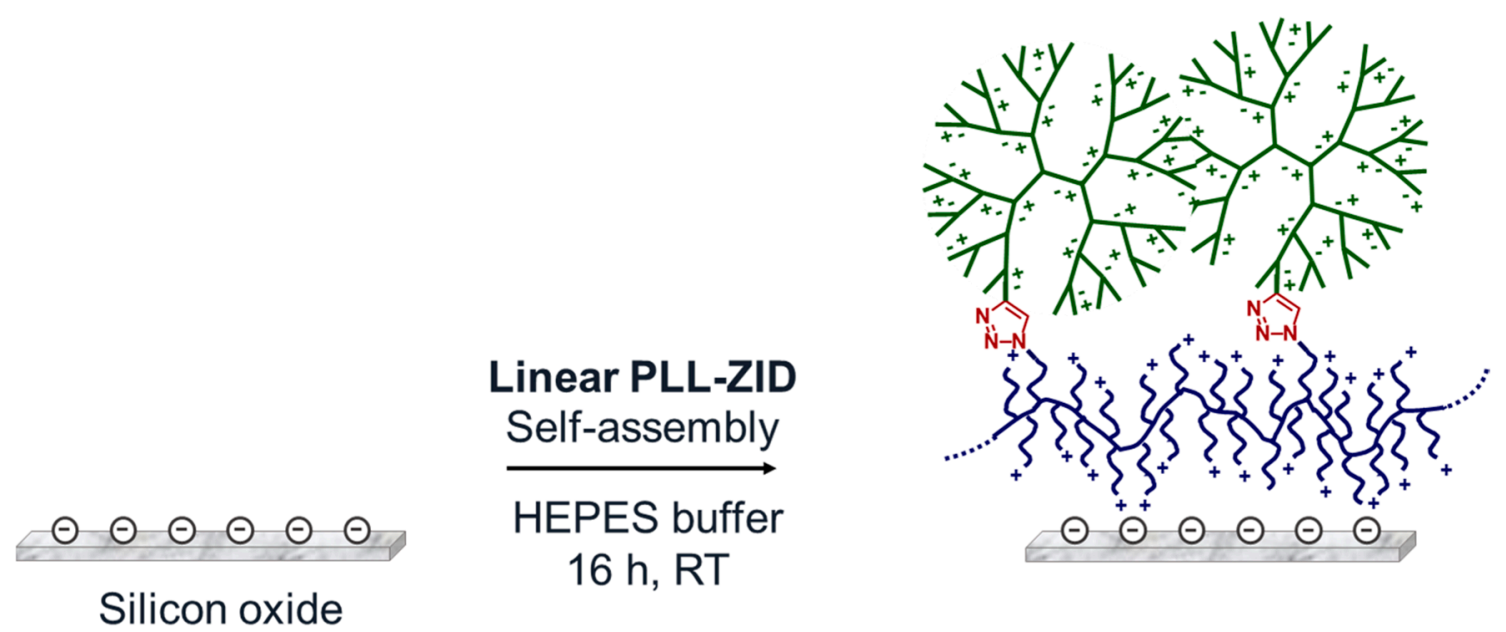

Fig. 9. Schematic depiction of the self-assembly of linear PLL-ZID Lin_A on silicon oxide.
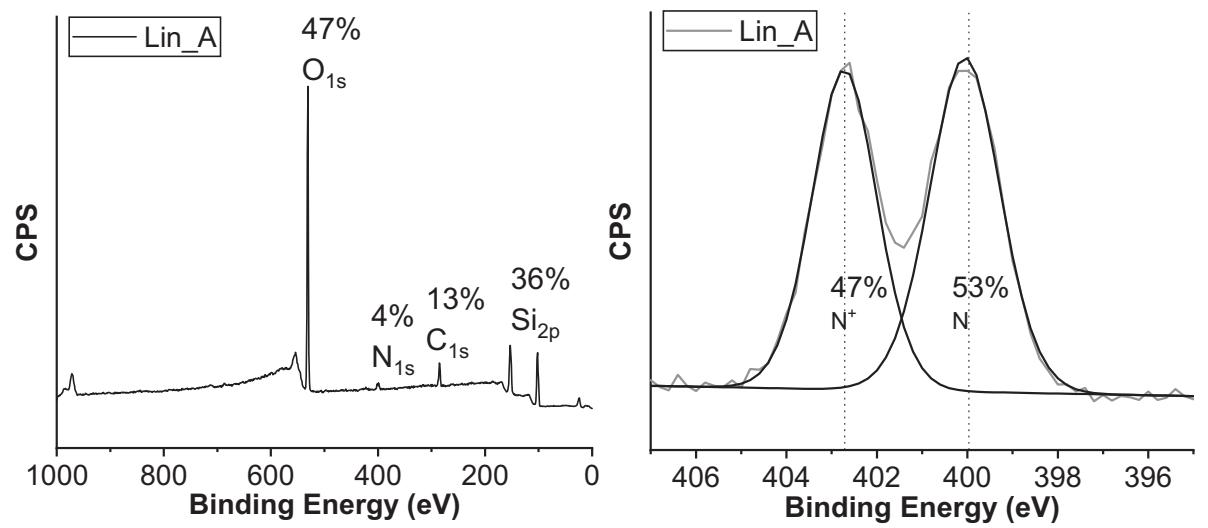

Fig. 10. XPS wide (left) and $\mathrm{N}_{1 \mathrm{~s}}$ narrow (right) spectra of surface-immobilized PLL-ZID Lin_A.

$\mathrm{eV})$, and quaternary $(403.0 \mathrm{eV})$ amines with a ratio of 53:47. Since the theoretical ratio at full conversion is $17: 25$, the conversion of the click reaction was estimated to be roughly $60 \%$. While this value is somewhat lower than the value obtained from the NMR integrations, this might be explained by the relatively small (and hence difficult to reliably integrate) azide signal needed for the NMR integration; in addition it means that loss of the IR azide signal does not imply full reaction, which can be partially attributed to peak broadening of the azide peaks due to the 
interaction of the polar azide groups with the highly polar ZID units. [62] Additionally, the coating made by linear PLL-ZID Lin_A was extremely hydrophilic and fully wetting when applying a droplet of water in order to determine the WCA. This extreme hydrophilicity is in line with the properties found for the PLL-ZID networks. In summary, we conclude the click conversion to have occurred with moderate to good yields. Given the size of the dendrimers that should click to the PLL backbone, and the concomitant steric hindrance, it is not surprising that the click reaction stopped before full conversion.

\subsection{Antifouling properties of the PLL-ZID based coatings}

\subsubsection{Fluorescence microscopy}

Having successfully synthesized and immobilized the different PLLZID coatings on silicon oxide surfaces, a preliminary investigation of their antifouling properties was performed. Firstly, the degree of fouling was related to the amount of protein adsorption by fluorescence microscopy, by exposing the coatings to fluorescently labelled singleprotein solutions [55,63-65]. In this study, lysozyme (LYS), bovine serum albumin (BSA) and fibrinogen (FIB) were used as model proteins at concentrations of $1 \mathrm{mg} / \mathrm{mL}$ in phosphate-buffered saline (PBS) and contacted with the surfaces for 15 min before washing with PBS. BSA was chosen since it is one of the most common proteins in blood plasma with an overall negative charge at $\mathrm{pH} 7.4$ (PBS buffer) [66]. LYS is a relatively small, hydrophilic protein and was used because of its overall positive charge at $\mathrm{pH} 7.4$ (PBS buffer)[67]. FIB was used as a more challenging fouling model protein since it plays a major role in clotting of the blood due to formation of fibrin networks, and platelet plug formation [68].

As controls for our single-protein adsorption experiments, we used bare silicon oxide surfaces and surfaces modified with commercially available PLL-PEG, which is known to have good single-protein antifouling properties [24]. In the fluorescence study, the unmodified blank silicon oxide surface showed higher fluorescence intensities from all protein solutions (Fig. 11), indicating significant fouling compared to all coated silicon oxide surfaces. Furthermore, the coating made by Netw_C (which contains the least ZID) showed most fouling of all the coated surfaces, especially in the case of BSA and FIB, though it still performed better than the blank surface. The other coatings Netw_B, Netw_A and Lin_A performed very similar to coatings made by commercially available PLL-PEG. It should be noted, however, that these data are close to the limit of detection for this method and close to the autofluorescence intensity as measured for an unexposed, blank silicon oxide surface. Therefore, using this method, we could not further differentiate between the antifouling performance of our synthesized coatings, in relation to the PLL-PEG coating.

\subsubsection{Quartz crystal microbalance}

To overcome these limitations, both type of coatings were further tested by an additional, more quantitative method: quartz crystal microbalance with dissipation monitoring (QCM-D) [69]. Recently, QCM$\mathrm{D}$ has emerged as a precise and reliable method to monitor and quantify surface adsorption from aqueous solutions onto a broad variety of surfaces [48,70-77]. QCM-D measures real-time resonating frequency and dissipation shifts of a quartz crystal resonator. These shifts can provide information on mass (frequency related) and physical properties (dissipation related) of an adsorbed layer on the quartz surface [69]. The recorded data can be modelled to further calculate viscoelastic properties (i.e. viscosity, elastic modulus) as well as wet thickness of the adsorbed layer using the Sauerbrey equation [78]. Hence, QCM-D offers a suitable and convenient tool to investigate protein adsorption on silicon oxide surfaces [70]. Netw_A was chosen as a representative for the PLL-ZID networks and measured alongside linear PLL-ZID Lin_A - which showed promising initial results - to compare to blank silicon and PLLPEG.

Starting from QCM-D sensors with a silicon oxide top layer, we were able to use the previously described protocol to coat these sensors with Lin_A, Netw_A or PLL-PEG. The frequency change of the QCM-D crystal upon passing of a solution of foulant through the QCM-D cell was monitored and compared to the response of non-modified, blank silicon oxide. The surface adsorption of bovine serum albumin (BSA), lysozyme (LYS), fibrinogen (FIB) and diluted human serum (HS) foulant solutions were monitored and quantified (Fig. 12).

All four tested foulant solutions showed a very similar response pattern. The sensor surface showed a stable baseline when being flushed with PBS buffer $(0-500 \mathrm{sec})$. Upon switching to the foulant solution, a distinct change in frequency was observed, that could be related to binding of foulant to the surface. After $2400 \mathrm{sec}$, when the medium was switched back to PBS buffer, the frequency dropped, which can be explained by the release of weakly bound protein. After equilibration, a certain fraction of protein was still bound, which was referred to as the level of fouling. As expected -and in line with the fluorescence microscopy results- all modified sensors (Lin_A, Netw_A and PLL-PEG) showed clearly less adsorption compared to the blank silicon oxide sensor. Furthermore, Lin_A outperformed Netw_A consistently by adsorbing less protein mass upon contact with all fouling solutions. We attribute this to the less defined system and limited flexibility of Netw_A coatings: whereas the system in Lin_A is free to self-organize at the surface - meaning the lysines pointing towards the surfaces while the ZIDs having an upward orientation - the random 3D networks in Netw_A might not have this freedom, leading to a coating with a toplayer that possesses a lower density of ZID.

The low adsorption of BSA $(10 \mathrm{mg} / \mathrm{mL}$, isoelectric point: 4.7 , MW:

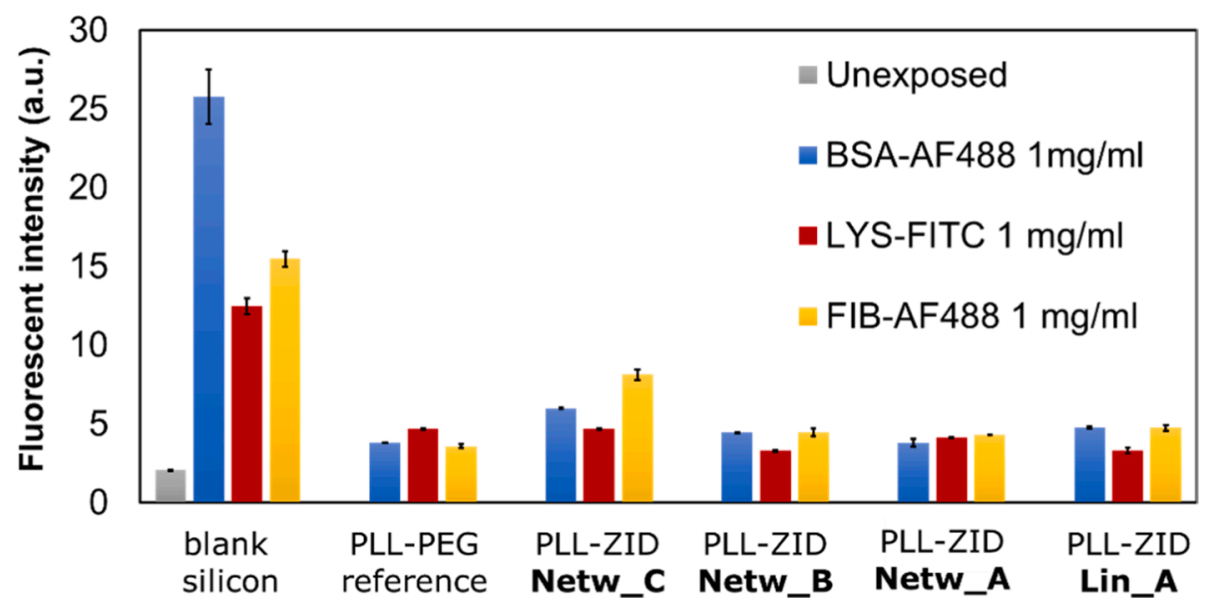

Fig. 11. Fluorescence intensities of uncoated and coated silicon oxide surfaces after exposure to solutions containing BSA-AF488, LYS-FITC or FIB-AF488. 

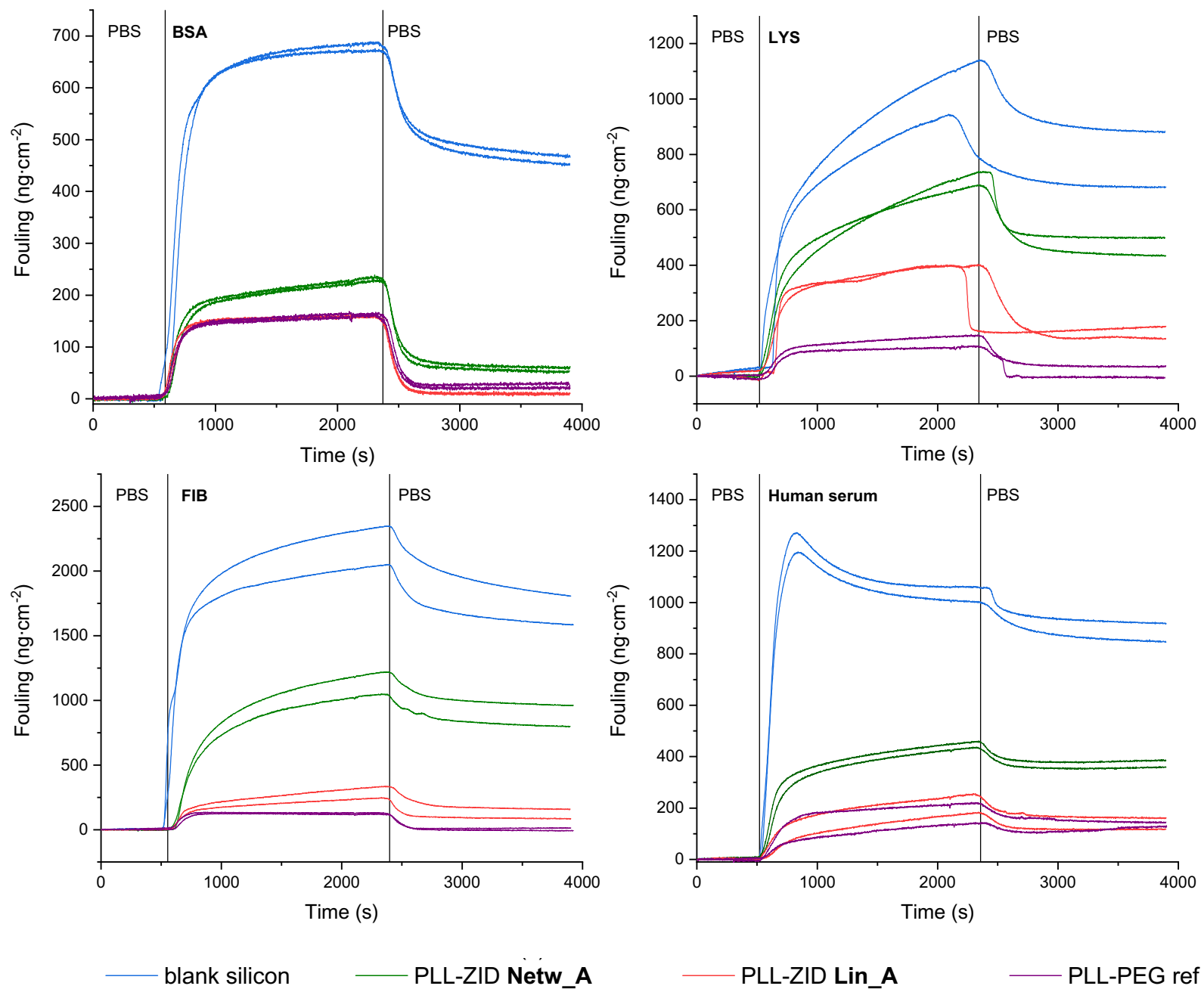

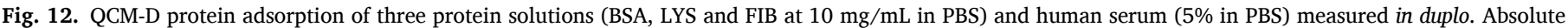
mass adsorptions were calculated from the frequency changes by using the Sauerbrey equation (see SI).

$66 \mathrm{kDa}$ ) on all modified sensors compared to the (less hydrophilic) unmodified silicon oxide sensor can be explained by the effective resistance of the coatings to fouling mediated by hydrophobic interactions. Especially the fact that the newly developed Lin_A outperforms the commercially available PLL-PEG $\left(\mathrm{WCA}=31^{\circ}\right.$ ), could be due to the more hydrophilic character of the Lin_A-based coating (WCA $<20^{\circ}$ ). Lysozyme $(10 \mathrm{mg} / \mathrm{mL}$, isoelectric point: 11 , MW: $14 \mathrm{kDa})$ was selected due to its net positive charge, in contrast to the negative charge of the other proteins tested, in order to assess the influence of electrostatic interactions. Both PLL-ZID-based coating showed increased adsorption in LYS fouling tests compared to BSA, but in both cases still lower than the uncoated silicon oxide surface. On the other hand, PLL-PEG showed very similar fouling as observed for BSA. Fouling by FIB $(10 \mathrm{mg} / \mathrm{mL}$; isoelectric point 5.7, MW: $340 \mathrm{kDa}$ ) was strongly reduced by Lin_A and PLL-PEG coatings. The excellent antifouling by PEG is in agreement with previous works showing resistance to fouling from FIB $[79,80]$. Compared to Lin_A and PLL-PEG, a higher fouling was observed on Netw_A, probably due to the less defined system, which might understandably also lead to less defined coatings. Amongst the tested singleprotein solutions, FIB showed to be most fouling, especially on the uncoated blank surface, which was previously observed in literature by SPR [81]. Next to testing the antifouling behavior of the coatings against single protein solutions, we also tested human serum (5\% in PBS) to more closely mimic the protein adsorption that would occur in biological fluids [82]. Both coatings by Netw_A and Lin_A showed clearly decreased fouling compared to the blank silicon oxide sensors. The newly developed Lin_A even performed equally well as the commercially available PLL-PEG, probably due to the more hydrophilic character of the Lin_A-based coating.

The newly developed PLL-ZID macrostructures - particularly Lin_A exhibited a decent resistance to fouling from single-protein solutions as well as diluted human serum, as revealed by fluorescence and QCM-D data. While the linear ZID-PLL platform does not yet meet the ultralow fouling levels as described in literature for the currently best performing coatings [54,55,83-89], the results are obtained with physiologically relevant protein concentrations $(10 \mathrm{mg} / \mathrm{mL})$ and contact times (30 $\mathrm{min}$ ) on a platform that involves only a single self-assembly step from an aqueous solution in an ambient atmosphere. Specifically, the low antifouling levels of $<1 \mathrm{ng} / \mathrm{cm}^{2}$ in single protein solutions such as BSA, LYS and FIB have frequently been shown for relatively thick ( $>30 \mathrm{~nm}$ ) zwitterionic polymer brush coatings using lower concentrations of proteins, such as $0.1 \mathrm{mg} / \mathrm{mL}$ and $1.0 \mathrm{mg} / \mathrm{mL}$ [90] and shorter fouling exposure times $(<30 \mathrm{~min})[65,88,90,91]$. In addition, those coatings were obtained by multiple-step surface-initiated controlled radical polymerizations usually in an inert atmosphere, which makes it -in contrast to our approach- difficult to scale up [7].

\subsection{Biofunctionalization}

To further develop the concept of PLL-ZID complexes as coatings, we also tested their potential for use as bio-interactive coatings which may find their application towards selective binding in, e.g., biosensors and 


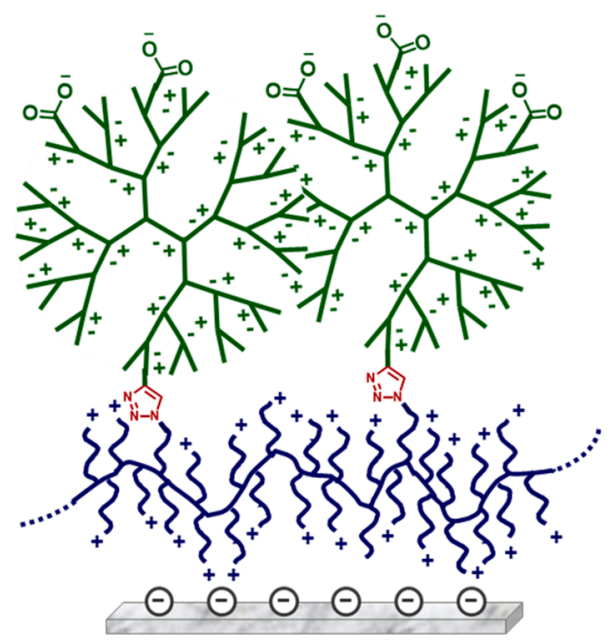

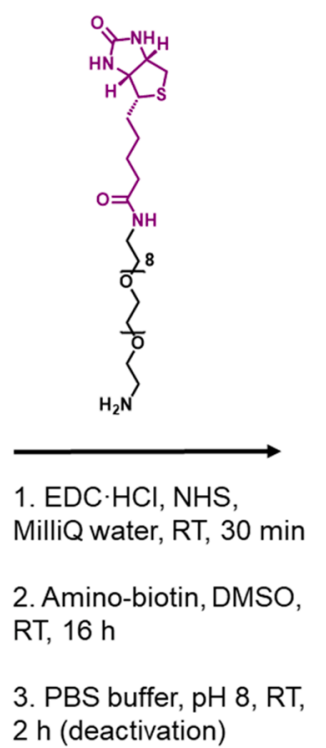

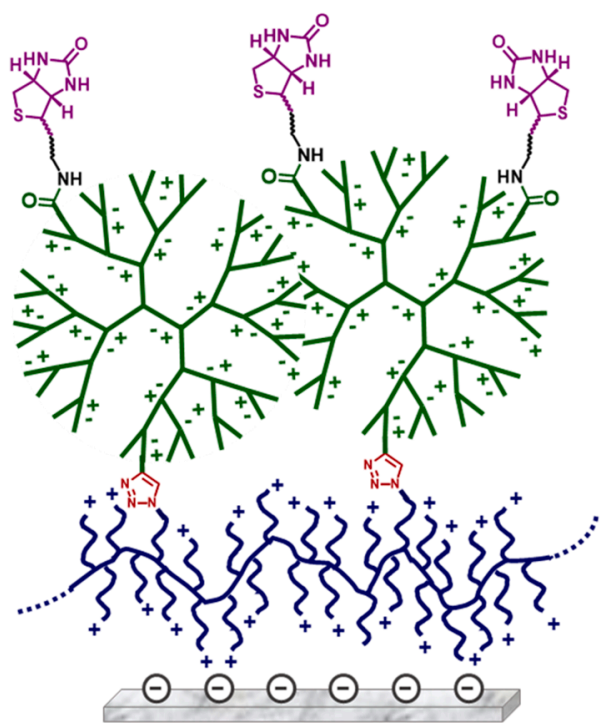

Fig. 13. Biotinylation of Lin_A PLL-ZID coated silicon oxide.

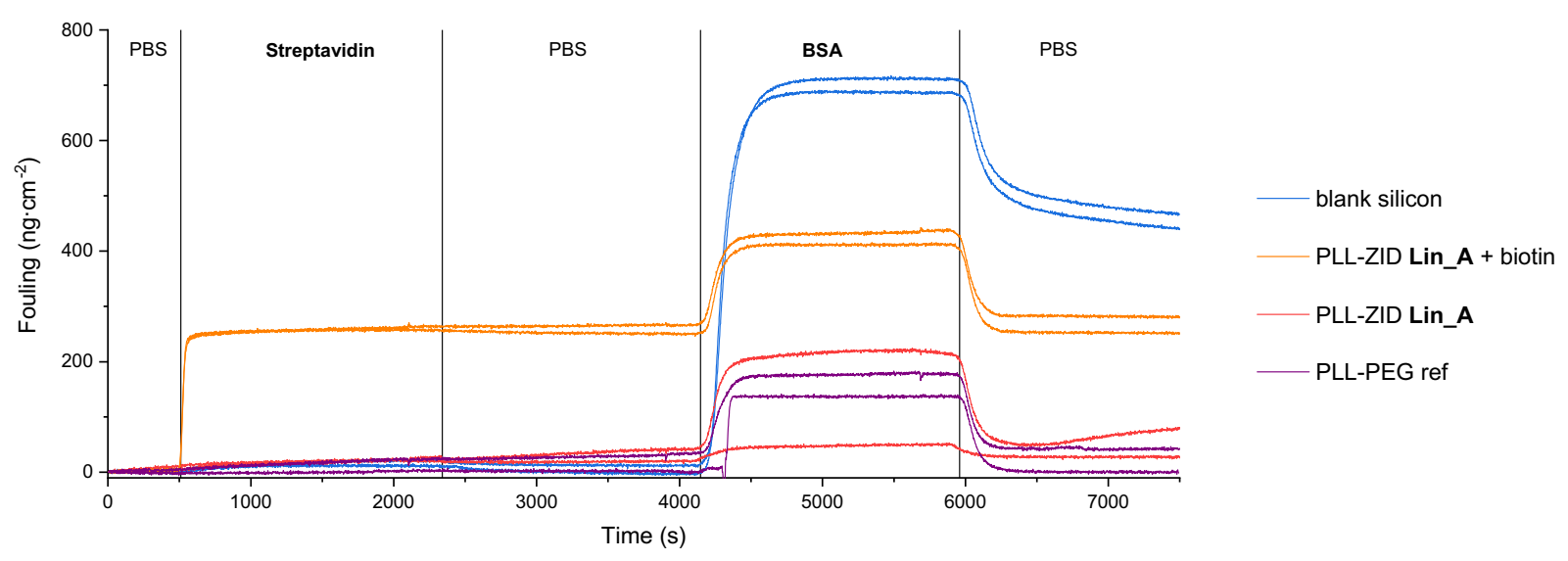

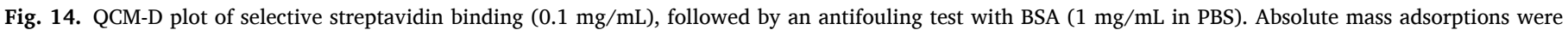
calculated from the frequency changes by using the Sauerbrey equation (see SI).

tissue engineering $[54,92,93]$. Since one of the most studied biointeractions is that between biotin and streptavidin, biotin was chosen as a functional group to be immobilized on the surface of the coating to selectively capture streptavidin. The binding between biotin and streptavidin is rapid and robust and therefore and ideal candidate to test bioselective interactions on our newly developed platform [94-96]. We selected the Lin_A-based coating to functionalize with biotin to be tested for bio-selective interactions with streptavidin, with the hypothesis that it would maintain its antifouling properties against BSA $(1 \mathrm{mg} / \mathrm{mL})$. After immobilizing Lin_A on a surface, free carboxylates on the dendrimer are still present on the surface. These carboxylate groups, allow for activation by NHS/EDC -in a manner similar to what we used for synthesis of the PLL-ZID networks- to couple a commercially available amino-functionalized biotin (Fig. 13) [55,97,98].

After functionalizing the Lin_A based coating on the QCM-D sensor with biotin, the coating was tested for bio-selective interactions with streptavidin whilst maintaining its antifouling properties against BSA (1 $\mathrm{mg} / \mathrm{mL}$ ). As controls, blank silicon oxide, non-biotinylated Lin_A and PLL-PEG were also monitored for their response towards streptavidin (Fig. 14). The sensors showed stable baselines when being flushed with PBS buffer (0-500 sec). Upon switching to a streptavidin solution ( 0.1 $\mathrm{mg} / \mathrm{mL}$ ), a distinct and very fast response was observed for only the biotinylated Lin_A. This indicated selective (and rapid) binding of streptavidin to the biotinylated Lin_A, whereas the other surfaces showed no clear signs of adsorption. After switching to PBS buffer, the signal remained stable, which indicates no release of streptavidin due to the strong binding of biotin-streptavidin [99]. To test if the Lin_A based coating maintained its antifouling properties after biotinylation and binding with streptavidin, a second test was performed by flushing a BSA solution (from 4100 to $5900 \mathrm{sec}$ ), followed by flushing with PBS for another $1500 \mathrm{sec}$. As anticipated, a similar response to the initial antifouling test (Fig. 12) was observed: a distinct change in frequency, related to binding of BSA to the surface, followed by a drop in signal upon switching back to PBS buffer caused by release of weakly bound protein. A quantitative comparison between the unfunctionalized and biotin-functionalized Lin_A coatings yielded a BSA adsorption of approximately 6 and $10 \mathrm{ng} / \mathrm{cm}^{2}$, respectively. This indicates that the antifouling properties of the biotinylated Lin_A were maintained, also after binding of streptavidin.

\section{Conclusions}

In this work we developed two different routes to synthesize polymer-dendrimer hybrids by the interconnection of PLL and ZID. The first route lead to network-like structures in which PLL and ZIDs were crosslinked by multiple amide bonds. By using different ratios of PLL and 
ZID, we could vary the size and PLL:ZID ratio in the formed networks. The second route lead to a more defined, linear PLL-ZID macromolecule, which was formed via click coupling of multiple ZIDs to a single PLL backbone. These two different types of PLL-ZID systems were then selfassembled onto silicon oxide surfaces from aqueous solutions in a single step, to form thin, hydrophilic coatings, which could be further biofunctionalized using the remaining carboxylate moieties in the coating. Especially the linear variant yielded good antifouling coatings towards single-protein solutions and diluted human serum, as shown in detail by using quartz crystal microbalance (QCM) for both the original as well as the biofunctionalized coatings. Given the ease with which these hybrid structures can be synthesized and surface-immobilized (single step, just immersing in aqueous solution under ambient conditions), these hybrid linear structures could be further studied, e.g., by focusing on different (lengths of) polymer backbones and/or different dendrimer (generations).

\section{Author statement}

The project was originally designed by Luc Scheres, Maarten Smulders and Han Zuilhof.

Esther Roeven did all experiments.

Maarten Smulders was her daily supervisor.

Luc Scheres, Maarten Smulders and Han Zuilhof undertook final supervision.

Refinement of the experiments needed to substantiate all conclusions was designed by all four authors, who also collaborated to interpret all data, and wrote the paper together.

\section{Declaration of Competing Interest}

The authors declare the following financial interests/personal relationships which may be considered as potential competing interests: Luc Scheres is CTO of Surfix B.V., one of the co-funders of this project.

\section{Data availability}

The raw data required to reproduce these findings are available to download from https://doi.org/10.4121/14035139. The processed data required to reproduce these findings are available to download from https://doi.org/10.4121/14035139.

\section{Acknowledgments}

This project was supported by Netherlands Organization for Scientific Research (NWO; LIFT program, grant 731.015.042) with Surfix BV as a partner. The authors thank Hans Beijleveld, Andriy Kuzmyn, Sevil Sahin and Barend van Lagen for helpful discussions and instrumental support.

\section{Appendix A. Supplementary material}

The Supporting Information contains a description of the used materials and methods, supporting NMR and IR data. Supplementary data to this article can be found online at https://doi.org/10.1016/j.eu rpolymj.2021.110578.

\section{References}

[1] U. Boas, J.B. Christensen, P.M.H. Heegaard, Dendrimers: design, synthesis and chemical properties, J. Mater. Chem. 16 (2006) 3785-3798, https://doi.org/ 10.1039/b611813p.

[2] K. Sato, J.I. Anzai, Dendrimers in layer-by-layer assemblies: Synthesis and applications, Molecules 18 (2013) 8440-8460, https://doi.org/10.3390/ molecules18078440.

[3] E. Abbasi, S.F. Aval, A. Akbarzadeh, M. Milani, H.T. Nasrabadi, S.W. Joo, Y. Hanifehpour, K. Nejati-Koshki, R. Pashaei-Asl, Dendrimers: Synthesis, applications, and properties, Nanoscale Res. Lett. 9 (2014) 1-10, https://doi.org/ $10.1186 / 1556-276 X-9-247$.

[4] C.C. Lee, J.A. MacKay, J.M.J. Fréchet, F.C. Szoka, Designing dendrimers for biological applications, Nat. Biotechnol. 23 (2005) 1517-1526, https://doi.org/ 10.1038/nbt1171.

[5] G.R. Newkome, C.D. Shreiner, Poly(amidoamine), polypropylenimine, and related dendrimers and dendrons possessing different $1 \rightarrow 2$ branching motifs: An overview of the divergent procedures, Polymer (Guildf). 49 (2008) 1-173, https:// doi.org/10.1016/J.POLYMER.2007.10.021.

[6] S. Nimesh, Gene Therapy: Potential Applications of Nanotechnology, Woodhead Publ. (2013), https://doi.org/10.1533/9781908818645.259.

[7] S. Jiang, Z. Cao, Ultralow-fouling, functionalizable, and hydrolyzable zwitterionic materials and their derivatives for biological applications, Adv. Mater. 22 (2010) 920-932, https://doi.org/10.1002/adma.200901407.

[8] J.B. Schlenoff, Zwitteration: Coating Surfaces with Zwitterionic Functionality to Reduce Nonspecific Adsorption, Langmuir 30 (2014) 9625-9636, https://doi.org/ 10.1021/la500057j.

[9] E.G.R. Fernandes, N.C.S. Vieira, A.A.A. de Queiroz, F.E.G. Guimarães, V. Zucolotto, Immobilization of Poly (propylene imine) Dendrimer/Nickel Phtalocyanine as Nanostructured Multilayer Films To Be Used as Gate Membranes for SEGFET pH Sensors, J. Phys. Chem. C. 114 (2010) 6478-6483.

[10] R. Schlapak, D. Armitage, N. Saucedo-zeni, G. Latini, H.J. Gruber, P. Mesquida, Y. Samotskaya, M. Hohage, F. Cacialli, S. Howorka, Preparation and Characterization of Dense Films of Poly (amidoamine) Dendrimers on Indium Tin Oxide, Langmuir 23 (2007) 8916-8924.

[11] L. Wang, Z. Wang, G. Ma, W. Lin, S. Chen, Reducing the cytotoxity of poly (amidoamine) dendrimers by modification of a single layer of carboxybetaine, Langmuir. 29 (2013) 8914-8921, https://doi.org/10.1021/la400623s.

[12] R.R. Ramireddy, A.V. Subrahmanyam, S. Thayumanavan, Zwitterionic moieties from the huisgen reaction: A case study with amphiphilic dendritic assemblies, Chem. Eur. J. 19 (2013) 16374-16381, https://doi.org/10.1002/ chem. 201302442.

[13] L. Li, Y. Wang, F. Ji, Y. Wen, J. Li, B. Yang, F. Yao, Synthesis and characterization of dendritic star-shaped zwitterionic polymers as novel anticancer drug delivery carriers, J. Biomater. Sci. Polym. Ed. 25 (2014) 1641-1657, https://doi.org/ 10.1080/09205063.2014.936994.

[14] L. Wang, J. Zhang, W. Lin, Z. Wang, S. Chen, Development of a Protein Mimic with Peptide Ligands to Enhance Specific Sensing and Targeting by the Zwitterionic Surface Engineering of Poly(amido amine) Dendrimers, Adv. Mater. Interfaces 1 (2014) 1300059, https://doi.org/10.1002/admi.201300059.

[15] Y. Wang, L. Li, J. Li, B. Yang, C. Wang, W. Fang, F. Ji, Y. Wen, F. Yao, Stable and $\mathrm{pH}$-responsive polyamidoamine based unimolecular micelles capped with a zwitterionic polymer shell for anticancer drug delivery, RSC Adv. 6 (2016) 17728-17739, https://doi.org/10.1039/C5RA25505H.

[16] S.W. Svenningsen, A. Janaszewska, M. Ficker, J.F. Petersen, B. KlajnertMaculewicz, J.B. Christensen, Two for the Price of One: PAMAM-Dendrimers with Mixed Phosphoryl Choline and Oligomeric Poly(Caprolactone) Surfaces, Bioconjug. Chem. 27 (2016) 1547-1557, https://doi.org/10.1021/acs. bioconjchem.6b00213.

[17] D. Huang, F. Yang, X. Wang, H. Shen, Y. You, D. Wu, Facile synthesis and selfassembly behaviour of $\mathrm{pH}$-responsive degradable polyacetal dendrimers, Polym. Chem. 7 (2016) 6154-6158, https://doi.org/10.1039/C6PY01511E.

[18] W. Cao, J. Huang, B. Jiang, X. Gao, P. Yang, Highly Selective Enrichment of Glycopeptides Based on Zwitterionically Functionalized Soluble Nanopolymers, Sci. Rep. 6 (2016) 1-8, https://doi.org/10.1038/srep29776.

[19] Y. Han, Y. Qian, X. Zhou, H. Hu, X. Liu, Z. Zhou, J. Tang, Y. Shen, Facile synthesis of zwitterionic polyglycerol dendrimers with a $\beta$-cyclodextrin core as MRI contrast agent carriers, Polym. Chem. 7 (2016) 6354, https://doi.org/10.1039/ C6PY01404F.

[20] Z. Xiong, Y. Wang, J. Zhu, X. Li, Y. He, J. Qu, M. Shen, J. Xia, X. Shi, Dendrimers meet zwitterions: Development of a unique antifouling nanoplatform for enhanced blood pool, lymph node and tumor CT imaging, Nanoscale. 9 (2017) 12295-12301, https://doi.org/10.1039/C7NR03940A.

[21] E. Roeven, L. Scheres, M.M.J. Smulders, H. Zuilhof, Design, Synthesis, and Characterization of Fully Zwitterionic, Functionalized Dendrimers, ACS Omega. 4 (2019) 3000-3011, https://doi.org/10.1021/acsomega.8b03521.

[22] R.E. Holmlin, X. Chen, R.G. Chapman, S. Takayama, G.M. Whitesides, Zwitterionic SAMs that Resist Nonspecific Adsorption of Protein from Aqueous Buffer, Langmuir 17 (2001) 2841-2850, https://doi.org/10.1021/la0015258.

[23] G.L. Kenausis, J. Vo, D.L. Elbert, N. Huang, R. Hofer, L. Ruiz-taylor, M. Textor, J. A. Hubbell, N.D. Spencer, Poly (L-lysine)-g-Poly(ethylene glycol) Layers on Metal Oxide Surfaces: Attachment Mechanism and Effects of Polymer Architecture on Resistance to Protein Adsorption, J. Phys. Chem. B. 104 (2000) 3298-3309.

[24] S.M. De Paul, J. Vo, N.D. Spencer, M. Textor, Poly(L-lysine)-graft-poly (ethylene glycol) Assembled Monolayers on Niobium Oxide Surfaces : A Quantitative Study of the Influence of Polymer Interfacial Architecture on Resistance to Protein Adsorption by ToF-SIMS and in Situ OWLS, Langmuir 19 (2003) 9216-9225, https://doi.org/10.1021/la034111y.

[25] G. Morgese, B. Verbraeken, S.N. Ramakrishna, Y. Gombert, E. Cavalli, J. G. Rosenboom, M. Zenobi-Wong, N.D. Spencer, R. Hoogenboom, E.M. Benetti, Chemical Design of Non-Ionic Polymer Brushes as Biointerfaces: Poly(2-oxazine)s Outperform Both Poly(2-oxazoline)s and PEG, Angew. Chem. Int. Ed. 57 (2018) 11667-11672, https://doi.org/10.1002/anie.201805620.

[26] S.S. Perry, X. Yan, F.T. Limpoco, S. Lee, M. Müller, N.D. Spencer, Tribological properties of poly(1 -lysine)- graft -poly(ethylene glycol) films: Influence of 
polymer architecture and adsorbed conformation, ACS Appl. Mater. Interfaces 1 (2009) 1224-1230, https://doi.org/10.1021/am900101m.

[27] W.M. Huang, S.J. Gibson, P. Facer, J. Gu, J.M. Polak, Improved section adhesion for immunocytochemistry using high molecular weight polymers of 1-lysine as a slide coating, Histochemistry 77 (1983) 275-279, https://doi.org/10.1007/ BF00506570.

[28] X. Yan, S.S. Perry, N.D. Spencer, S. Pasche, S.M. De Paul, M. Textor, M.S. Lim, Reduction of Friction at Oxide Interfaces upon Polymer Adsorption from Aqueous Solutions, Langmuir 20 (2004) 423-428, https://doi.org/10.1021/la035785b.

[29] G.A. Parks, The Isoelectric Points of Solid Oxides, Solid Hydroxides, and Aqueous Hydroxo Complex Systems, Chem. Rev. 65 (1965) 177-198, https://doi.org/ 10.1021/cr60234a002.

[30] D. Weber, B. Torger, K. Richter, M. Nessling, F. Momburg, B. Woltmann, M. Müller, R. Schwartz-Albiez, Interaction of poly(L-lysine)/polysaccharide complex nanoparticles with human vascular endothelial cells, Nanomaterials 8 (2018) 358, https://doi.org/10.3390/nano8060358.

[31] E. Roeven, A.R. Kuzmyn, L. Scheres, J. Baggerman, M.M.J. Smulders, H. Zuilhof, PLL-Poly(HPMA) Bottlebrush-Based Antifouling Coatings: Three Grafting Routes, Langmuir 36 (2020) 10187-10199, https://doi.org/10.1021/acs. langmuir.0c01675.

[32] I. Gitsov, K.L. Wooley, Novel Polyether Copolymers Consisting of Linear and Dendritic Blocks, Angew. Chem. Int. Ed. 31 (1992) 1200-1202.

[33] A. Sousa-Herves, R. Riguera, E. Fernandez-Megia, PEG-dendritic block copolymers for biomedical applications, New J. Chem. 36 (2012) 205-210, https://doi.org/ 10.1039/c2nj20849k.

[34] H. Sun, F.M. Haque, Y. Zhang, A. Commisso, M.A. Mohamed, M. Tsianou, H. Cui, S. M. Grayson, C. Cheng, Linear-Dendritic Alternating Copolymers, Angew. Chem. Int. Ed. 58 (2019) 10572-10576, https://doi.org/10.1002/anie.201903402.

[35] T.M. Chapman, G.L. Hillyer, E.J. Mahan, K.A. Shaffer, Hydraamphiphiles: Novel Linear Dendritic Block Copolymer Surfactants, J. Am. Chem. Soc. 116 (1994) 11195-11196, https://doi.org/10.1021/ja00103a060.

[36] J.C.M. van Hest, D.A.P. Delnoye, M.W.P.L. Baars, M.H.P. van Genderen, E. W. Meijer, Polystyrene-Dendrimer Amphiphilic Block Copolymers with a Generation-Dependent Aggregation, Science 268 (1995) 1592-1595, https://doi. org/10.1126/science.268.5217.1592.

[37] J. Iyer, K. Fleming, P.T. Hammond, Synthesis and solution properties of new lineardendritic diblock copolymers, Macromolecules 31 (1998) 8757-8765, https://doi. org/10.1021/ma980654g.

[38] R.C. Hedden, B.J. Bauer, A. Paul Smith, F. Gröhn, E. Amis, Templating of inorganic nanoparticles by PAMAM/PEG dendrimer - Star polymers, Polymer 43 (2002) 5473-5481, https://doi.org/10.1016/S0032-3861(02)00428-7.

[39] C.C. Lee, E.R. Gillies, M.E. Fox, S.J. Guillaudeu, J.M.J. Fréchet, E.E. Dy, F.C. Szoka, A single dose of doxorubicin-functionalized bow-tie dendrimer cures mice bearing C-26 colon carcinomas, Proc. Natl. Acad. Sci. U. S. A. 103 (2006) 16649-16654, https://doi.org/10.1073/pnas.0607705103.

[40] R. Kaup, J. Bart, A.H. Velders, Dendroids, Discrete Covalently Cross-Linked Dendrimer Superstructures, ACS Nano. 15 (2020) 1666-1674, https://doi.org/ 10.1021/acsnano.0c09322.

[41] H. Frauenrath, Dendronized polymers - Building a new bridge from molecules to nanoscopic objects, Prog. Polym. Sci. 30 (2005) 325-384, https://doi.org/ 10.1016/j.progpolymsci.2005.01.011.

[42] Y. Zhang, X. Li, G. Deng, Y. Chen, Novel hybrid polymer brushes with alternating dendritic wedges and linear side chains, Macromol. Chem. Phys. 207 (2006) 1394-1403, https://doi.org/10.1002/macp.200600184.

[43] Y. Shi, W. Zhu, Y. Chen, Synthesis of cylindrical polymer brushes with umbrellalike side chains via a combination of grafting-from and grafting-onto methods, Macromolecules 46 (2013) 2391-2398, https://doi.org/10.1021/ma4001463.

[44] O.C.J. Andrén, Y. Zhang, P. Lundberg, C.J. Hawker, A.M. Nyström, M. Malkoch, Therapeutic Nanocarriers via Cholesterol Directed Self-Assembly of Well-Defined Linear-Dendritic Polymeric Amphiphiles, Chem. Mater. 29 (2017) 3891-3898, https://doi.org/10.1021/acs.chemmater.6b05095.

[45] V.V. Rostovtsev, L.G. Green, V.V. Fokin, K.B. Sharpless, A stepwise huisgen cycloaddition process: Copper(I)-catalyzed regioselective "ligation" of azides and terminal alkynes, Angew. Chem. Int. Ed. Engl. 41 (2002) 2596-2599, https://doi. org/10.1002/1521-3773(20020715)41:14<2596::AID-ANIE2596>3.0.CO;2-4.

[46] D. Thomson, A. Zilkie, J.E. Bowers, T. Komljenovic, G.T. Reed, L. Vivien, D. MarrisMorini, E. Cassan, L. Virot, J.M. Fédéli, J.M. Hartmann, J.H. Schmid, D.X. Xu, F. Boeuf, P. O'Brien, G.Z. Mashanovich, M. Nedeljkovic, Roadmap on silicon photonics, J. Opt. 18 (2016) 1-20, https://doi.org/10.1088/2040-8978/18/7/ 073003.

[47] Z.B. Qi, L. Xu, Y. Xu, J. Zhong, A. Abedini, X. Cheng, D. Sinton, Disposable siliconglass microfluidic devices: Precise, robust and cheap, Lab Chip. 18 (2018) 3872-3880, https://doi.org/10.1039/c8lc01109e.

[48] F.F. Hook, J. Vörös, M. Rodahl, R. Kurrat, P. Böni, J.J. Ramsden, M. Textor, N. D. Spencer, P. Tengvall, J. Gold, B. Kasemo, A comparative study of protein adsorption on titanium oxide surfaces using in situ ellipsometry, optical waveguide lightmode spectroscopy, and quartz crystal microbalance/dissipation, Colloids Surf. B Biointerfaces. 24 (2002) 155-170, https://doi.org/10.1016/S0927-7765 (01)00236-3.

[49] G. Besselink, R. Heideman, E. Schreuder, L. Wevers, F. Falke, H. Van den Vlekkert, Performance of Arrayed Microring Resonator Sensors with the TriPleX Platform, J. Biosens. Bioelectron. 7 (2016) 1000209, https://doi.org/10.4172/21556210.1000209.

[50] E. Gedig, Surface chemistry in SPR technology, Handb. Surf. Plasmon Reson. (2008) 173-220, https://doi.org/10.1039/9781847558220-00173.
[51] A. Wörz, B. Berchtold, K. Moosmann, O. Prucker, J. Rühe, Protein-resistant polymer surfaces, J. Mater. Chem. 22 (2012) 19547, https://doi.org/10.1039/ c2jm30820g.

[52] J. Xu, Q. Yu, S. Jiang, Cellulose Paper Sensors Modified with Zwitterionic Poly (carboxybetaine) for Sensing and Detection in Complex Media, Anal. Chem. 86 (2014) 2871-2875, https://doi.org/10.1021/ac500467c.

[53] Z. Zhang, S. Chen, S. Jiang, Dual-Functional Biomimetic Materials: Nonfouling Poly (carboxybetaine) with Active Functional Groups for Protein Immobilization, Biomacromolecules 7 (2006) 3311-3315, https://doi.org/10.1021/bm060750m.

[54] J. Baggerman, M.M.J. Smulders, H. Zuilhof, Romantic Surfaces: A Systematic Overview of Stable, Biospecific, and Antifouling Zwitterionic Surfaces, Langmuir. 35 (2019) 1072-1084, https://doi.org/10.1021/acs.langmuir.8b03360.

[55] A.R. Kuzmyn, A.T. Nguyen, H. Zuilhof, J. Baggerman, Bioactive Antifouling Surfaces by Visible-Light-Triggered Polymerization, Adv. Mater. Interfaces. 6 (2019) 1900351, https://doi.org/10.1002/admi.201900351.

[56] D. Volodkin, V. Ball, P. Schaaf, J.C. Voegel, H. Mohwald, Complexation of phosphocholine liposomes with polylysine. Stabilization by surface coverage versus aggregation, Biochim. Biophys. Acta. 1768 (2007) 280-290, https://doi. org /10.1016/j.bbamem.2006.09.015.

[57] A. Laschewsky, Structures and synthesis of zwitterionic polymers, Polymers 6 (2014) 1544-1601, https://doi.org/10.3390/polym6051544.

[58] M.P. Wickramathilaka, B.Y. Tao, Characterization of covalent crosslinking strategies for synthesizing DNA-based bioconjugates, J. Biol. Eng. 13 (2019) 63, https://doi.org/10.1186/s13036-019-0191-2.

[59] R.K. Smith, P.A. Lewis, P.S. Weiss, Patterning self-assembled monolayers, Prog. Surf. Sci. 75 (2004) 1-68, https://doi.org/10.1016/j.progsurf.2003.12.001.

[60] X. Wallart, C. Henry de Villeneuve, P. Allongue, Truly quantitative XPS characterization of organic monolayers on silicon: study of alkyl and alkoxy monolayers on H-Si(111), J. Am. Chem. Soc. 127 (2005) 7871-7878, https://doi. org/10.1021/ja0430797.

[61] L. Scheres, M. Giesbers, H. Zuilhof, Organic monolayers onto oxide-free silicon with improved surface coverage: Alkynes versus alkenes, Langmuir 26 (2010) 4790-4795, https://doi.org/10.1021/la9035503.

[62] L. Scheres, M. Giesbers, H. Zuilhof, Self-assembly of organic monolayers onto hydrogen-terminated silicon: 1-alkynes are better than 1-alkenes, Langmuir 26 (2010) 10924-10929, https://doi.org/10.1021/la100858q.

[63] T. Honda, A. Nakao, K. Ishihara, Y. Higaki, K. Higaki, A. Takahara, Y. Iwasaki, S. I. Yusa, Polymer coating glass to improve the protein antifouling effect, Polym. J. 50 (2018) 381-388, https://doi.org/10.1038/s41428-018-0026-x.

[64] L.Q. Xu, D. Pranantyo, K.G. Neoh, E.T. Kang, S.L.M. Teo, G.D. Fu, Synthesis of catechol and zwitterion-bifunctionalized poly(ethylene glycol) for the construction of antifouling surfaces, Polym. Chem. 7 (2016) 493-501, https://doi.org/10.1039/ c5py01234a.

[65] A.R. Kuzmyn, A.T. Nguyen, L.W. Teunissen, H. Zuilhof, J. Baggerman, Antifouling Polymer Brushes via Oxygen-Tolerant Surface-Initiated PET-RAFT, Langmuir 36 (2020) 4439-4446, https://doi.org/10.1021/acs.langmuir.9b03536.

[66] H.M. Kowalczyńska, M. Nowak-Wyrzykowska, A.A. Szczepankiewicz, J. Dobkowski, M. Dyda, J. Kamiński, R. Kołos, Albumin adsorption on unmodified and sulfonated polystyrene surfaces, in relation to cell-substratum adhesion, Colloids Surf. B Biointerfaces 84 (2011) 536-544, https://doi.org/10.1016/j. colsurfb.2011.02.013.

[67] W.S. Price, F. Tsuchiya, Y. Arata, Lysozyme aggregation and solution properties studied using PGSE NMR diffusion measurements, J. Am. Chem. Soc. 121 (1999) 11503-11512, https://doi.org/10.1021/ja992265n.

[68] T.A. Horbett, Fibrinogen adsorption to biomaterials, J. Biomed. Mater. Res. A. 106 (2018) 2777-2788, https://doi.org/10.1002/jbm.a.36460.

[69] C. Tonda-Turo, I. Carmagnola, G. Ciardelli, Quartz crystal microbalance with dissipation monitoring: A powerful method to predict the in vivo behavior of bioengineered surfaces, Front. Bioeng. Biotechnol. 6 (2018) 1-7, https://doi.org/ 10.3389/fbioe.2018.00158.

[70] N. Chandrasekaran, S. Dimartino, C.J. Fee, Study of the adsorption of proteins on stainless steel surfaces using QCM-D, Chem. Eng. Res. Des. 91 (2013) 1674-1683, https://doi.org/10.1016/j.cherd.2013.07.017.

[71] A. Janshoff, H.J. Galla, C. Steinem, Piezoelectric mass-sensing devices as biosensors - An alternative to optical biosensors? Angew. Chem. Int. Ed. 39 (2000) 4004-4032, https://doi.org/10.1002/1521-3773(20001117)39:22<4004::AIDANIE4004>3.0.CO;2-2.

[72] H.T.M. Phan, S. Bartelt-Hunt, K.B. Rodenhausen, M. Schubert, J.C. Bartz, Investigation of bovine serum albumin (BSA) attachment onto self-assembled monolayers (SAMs) using combinatorial quartz crystal microbalance with dissipation (QCM-D) and spectroscopic ellipsometry (SE), PLoS One 10 (2015), https://doi.org/10.1371/journal.pone.0141282.

[73] R. Yang, K.K. Gleason, Ultrathin antifouling coatings with stable surface zwitterionic functionality by initiated chemical vapor deposition (iCVD), Langmuir 28 (2012) 12266-12274, https://doi.org/10.1021/la302059s.

[74] X. Wang, B. Cheng, C. Ji, M. Zhou, L. Wang, Effects of hydraulic retention time on adsorption behaviours of EPS in an A/O-MBR: Biofouling study with QCM-D, Sci. Rep. 7 (2017) 1-9, https://doi.org/10.1038/s41598-017-03190-1.

[75] T.E. Alexander, L.D. Lozeau, T.A. Camesano, QCM-D characterization of timedependence of bacterial adhesion, Cell Surf. 5 (2019) 100024, https://doi.org/ 10.1016/j.tcsw.2019.100024.

[76] D. Shen, M. Huang, L. Chow, M. Yang, Kinetic profile of the adsorption and conformational change of lysozyme on self-assembled monolayers as revealed by quartz crystal resonator, Sens. Actuators B. 77 (2001) 664-670. 
[77] N. Bellassai, A. Marti, G. Spoto, Low-fouling, mixed-charge poly-l-lysine polymers with anionic oligopeptide side-chains, J. Mater. Chem. B. 6 (2018) 7662-7673, https://doi.org/10.1039/c8tb01619d.

[78] M. Rodahl, F. Höök, B. Kasemo, QCM operation in liquids: An explanation of measured variations in frequency and $\mathrm{Q}$ factor with liquid conductivity, Anal. Chem. 68 (1996) 2219-2227, https://doi.org/10.1021/ac951203m.

[79] K.L. Prime, G.M. Whitesides, Adsorption of Proteins onto Surfaces Containing EndAttached Oligo(ethylene oxide): A Model System Using Self-Assembled Monolayers, J. Am. Chem. Soc. 115 (1993) 10714-10721, https://doi.org/ 10.1021/ja00076a032.

[80] P. Harder, M. Grunze, R. Dahint, Molecular Conformation in Oligo(ethylene glycol)-Terminated Self-Assembled Monolayers on Gold and Silver Surfaces Determines Their Ability To Resist Protein Adsorption, J. Phys. Chem. B. 5647 (1998) 426-436.

[81] C.R. Emmenegger, E. Brynda, T. Riedel, Z. Sedlakova, M. Houska, A.B. Alles, Interaction of Blood Plasma with Antifouling Surfaces, Langmuir 25 (2009) 6328-6333, https://doi.org/10.1021/la900083s.

[82] A.L.S. Burzava, M. Jasieniak, M.P. Cockshell, N.H. Voelcker, C.S. Bonder, H. J. Griesser, E. Moore, Surface-Grafted Hyperbranched Polyglycerol Coating: Varying Extents of Fouling Resistance across a Range of Proteins and Cells, ACS Appl. Bio Mater. 3 (2020) 3718-3730, https://doi.org/10.1021/acsabm.0c00336.

[83] E. van Andel, I. de Bus, E.J. Tijhaar, M.M.J. Smulders, H.F.J. Savelkoul, H. Zuilhof, Highly Specific Binding on Antifouling Zwitterionic Polymer-Coated Microbeads as Measured by Flow Cytometry, ACS Appl. Mater. Interfaces 9 (2017) 38211-38221, https://doi.org/10.1021/acsami.7b09725.

[84] W. Yang, S. Chen, G. Cheng, H. Vaisocherová, H. Xue, W. Li, J. Zhang, S. Jiang, Film thickness dependence of protein adsorption from blood serum and plasma onto poly(sulfobetaine)-grafted surfaces, Langmuir 24 (2008) 9211-9214, https:// doi.org/10.1021/la801487f.

[85] J. Koc, E. Schönemann, A. Amuthalingam, J. Clarke, J.A. Finlay, A.S. Clare, A. Laschewsky, A. Rosenhahn, Low-Fouling Thin Hydrogel Coatings Made of Photo-Cross-Linked Polyzwitterions, Langmuir 35 (2019) 1552-1562, https://doi org/10.1021/acs.langmuir.8b02799.

[86] E. Van Andel, S.C. Lange, S.P. Pujari, E.J. Tijhaar, M.M.J. Smulders, H.F. J. Savelkoul, H. Zuilhof, Systematic Comparison of Zwitterionic and NonZwitterionic Antifouling Polymer Brushes on a Bead-Based Platform, Langmuir 35 (2019) 1181-1191, https://doi.org/10.1021/acs.langmuir.8b01832.

[87] M. Vorobii, A. de los Santos Pereira, O. Pop-Georgievski, N.Y. Kostina, C. Rodriguez-Emmenegger, V. Percec, Synthesis of non-fouling poly[N-(2hydroxypropyl)methacrylamide] brushes by photoinduced SET-LRP, Polym. Chem. 6 (2015) 4210-4220, https://doi.org/10.1039/C5PY00506J.

[88] C. Rodriguez-Emmenegger, E. Brynda, T. Riedel, M. Houska, V. Šubr, A.B. Alles, E. Hasan, J.E. Gautrot, W.T.S. Huck, Polymer brushes showing non-fouling in blood plasma challenge the currently accepted design of protein resistant surfaces,
Macromol. Rapid Commun. 32 (2011) 952-957, https://doi.org/10.1002/ marc. 201100189.

[89] F. Surman, T. Riedel, M. Bruns, N.Y. Kostina, Z. Sedláková, C. RodriguezEmmenegger, Polymer brushes interfacing blood as a route toward high performance blood contacting devices, Macromol. Biosci. 15 (2015) 636-646, https://doi.org/10.1002/mabi.201400470.

[90] B. Cao, L. Li, Q. Tang, G. Cheng, The impact of structure on elasticity, switchability, stability and functionality of an all-in-one carboxybetaine elastomer, Biomaterials 34 (2013) 7592-7600, https://doi.org/10.1016/j.biomaterials.2013.06.063.

[91] R. Chen, Y. Ma, C. Zhao, Z. Lin, X. Zhu, L. Zhang, W. Yang, Construction of DNA microarrays on cyclic olefin copolymer surfaces using confined photocatalytic oxidation, RSC Adv. 4 (2014) 46653-46661, https://doi.org/10.1039/ C4RA07442D.

[92] A. Xiao, C. Dhand, C.M. Leung, R.W. Beuerman, S. Ramakrishna, R. Lakshminarayanan, Strategies to design antimicrobial contact lenses and contact lens cases, J. Mater. Chem. B. 6 (2018) 2171-2186, https://doi.org/10.1039/ c7tb03136j.

[93] R. Poręba, A. de los Santos Pereira, R. Pola, S. Jiang, O. Pop-Georgievski, Z. Sedláková, H. Schönherr, "Clickable" and Antifouling Block Copolymer Brushes as a Versatile Platform for Peptide-Specific Cell Attachment, Macromol. Biosci. 20 (2020) 1900354, https://doi.org/10.1002/mabi.201900354.

[94] S.C. Lange, E. Van Andel, M.M.J. Smulders, H. Zuilhof, Efficient and tunable threedimensional functionalization of fully zwitterionic antifouling surface coatings, Langmuir 32 (2016) 10199-10205, https://doi.org/10.1021/acs. langmuir.6b02622.

[95] E. Morag, E.A. Bayer, M. Wilchek, Reversibility of biotin-binding by selective modification of tyrosine in avidin, Biochem. J. 316 (1996) 193-199, https://doi. org/10.1042/bj3160193.

[96] U. Piran, W.J. Riordan, Dissociation rate constant of the biotin-streptavidin complex, J. Immunol. Methods 133 (1990) 141-143, https://doi.org/10.1016/ 0022-1759(90)90328-S.

[97] M. Krishnamoorthy, S. Hakobyan, M. Ramstedt, J.E. Gautrot, Surface-Initiated Polymer Brushes in the Biomedical Field: Applications in Membrane Science, Biosensing, Cell Culture, Regenerative Medicine and Antibacterial Coatings, Chem. Rev. 114 (2014) 10976-11026, https://doi.org/10.1021/cr500252u.

[98] H. Vaisocherová, W. Yang, Z. Zhang, Z. Cao, G. Cheng, M. Piliarik, J. Homola, S. Jiang, Ultralow fouling and functionalizable surface chemistry based on a zwitterionic polymer enabling sensitive and specific protein detection in undiluted blood plasma, Anal. Chem. 80 (2008) 7894-7901, https://doi.org/10.1021/ ac8015888.

[99] S. Joshi, P. Pellacani, T.A. van Beek, H. Zuilhof, M.W.F. Nielen, Surface characterization and antifouling properties of nanostructured gold chips for imaging surface plasmon resonance biosensing, Sens. Actuators B. 209 (2015) 505-514, https://doi.org/10.1016/j.snb.2014.11.133. 